\title{
Antidepressant Flavonoids and Their Relationship with Oxidative Stress
}

\author{
Lucian Hritcu, ${ }^{1}$ Radu Ionita, ${ }^{1}$ Paula Alexandra Postu, ${ }^{1}$ Girish Kumar Gupta, ${ }^{2}$ \\ Hasan Turkez, ${ }^{3}$ Tamires Cardoso Lima, ${ }^{4}$ Caroline Uchôa Souza Carvalho, ${ }^{5}$ \\ and Damião Pergentino de Sousa ${ }^{5}$ \\ ${ }^{1}$ Department of Biology, Alexandru Ioan Cuza University of Iasi, Bd. Carol I No. 11, 700506 Iasi, Romania \\ ${ }^{2}$ Department of Pharmaceutical Chemistry, M. M. College of Pharmacy, Mullana, Maharishi Markandeshwar University, Ambala, \\ Haryana 133203, India \\ ${ }^{3}$ Department of Molecular Biology and Genetics, Erzurum Technical University, 25000 Erzurum, Turkey \\ ${ }^{4}$ Departamento de Farmácia, Universidade Federal de Sergipe, 49100-000 São Cristóvão, SE, Brazil \\ ${ }^{5}$ Departamento de Ciências Farmacêuticas, Universidade Federal da Paraíba, 58051-970 João Pessoa, PB, Brazil
}

Correspondence should be addressed to Damião Pergentino de Sousa; damiao_desousa@yahoo.com.br

Received 7 September 2017; Accepted 22 November 2017; Published 19 December 2017

Academic Editor: Kota V. Ramana

Copyright (c) 2017 Lucian Hritcu et al. This is an open access article distributed under the Creative Commons Attribution License, which permits unrestricted use, distribution, and reproduction in any medium, provided the original work is properly cited.

Depression is a serious disorder that affects hundreds of millions of people around the world and causes poor quality of life, problem behaviors, and limitations in activities of daily living. Therefore, the search for new therapeutic options is of high interest and growth. Research on the relationship between depression and oxidative stress has shown important biochemical aspects in the development of this disease. Flavonoids are a class of natural products that exhibit several pharmacological properties, including antidepressant-like activity, and affects various physiological and biochemical functions in the body. Studies show the clinical potential of antioxidant flavonoids in treating depressive disorders and strongly suggest that these natural products are interesting prototype compounds in the study of new antidepressant drugs. So, this review will summarize the chemical and pharmacological perspectives related to the discovery of flavonoids with antidepressant activity. The mechanisms of action of these compounds are also discussed, including their actions on oxidative stress relating to depression.

\section{Introduction}

Besides cognitive deficits, Alzheimer's disease (AD) is characterized by noncognitive features which are the behavioral and psychological symptoms of dementia (BPSD) [1]. Of all the BPSD, the prevalence of depression is the most noteworthy, at $40 \%$ [2], and could be considered to be a risk factor for $\mathrm{AD}$ [3]. The neurotoxic effects of depression include atrophy of hippocampus linked to over secretion of cortisol or abnormally low concentration of brain-derived neurotrophic factor (BDNF) [4]. Furthermore, it has been recommended that depression could be induced by metabolic disorders of monoamine neurotransmitters that are engaged in noradrenaline (NE), serotonin (5-HT), and dopamine (DA) signaling
[5]. Anxiety and depression have been shown to increase the severity of cognitive decline in $\mathrm{AD}$ patients [6]. Furthermore, anxiety is more common in individuals with dementia than in individuals without dementia [7] and it is associated with worse quality of life, problem behaviors, impediments in activities of daily living, nighttime awakenings, and poorer neuropsychological performance, even after controlling for depression [8]. The World Health Organization (WHO) estimates that around 350 million individuals suffer from depression and anticipates that by 2020 the disorder will be the second driving reason of disability worldwide. As of now, there are numerous effective antidepressants available, yet a few antidepressants caused insufficient and unsatisfactory results in around $33 \%$ of all subjects treated [9-11]. 
Along these lines, endeavors ought to be sought after for the development of the newer antidepressant agents with better efficacy and fewer side effects.

The different forms of monoamine oxidases (MAO-A and MAO-B) were considered as relevant for key events in intrinsic cell death pathways, particularly those focused on oxidative stress and peroxyradical-mediated mechanisms via causing to the production of hydrogen peroxide as a byproduct of the reaction between the MAOs (monoamine oxidases) and their monoamine substrates [12]. Especially the upregulation of $\mathrm{MAO}-\mathrm{A}$ prompted increments of 5hydroxyindoleacetic acid/5-HT ratio, oxidative stress, leading to nuclear factor $-\kappa \mathrm{B}(\mathrm{NF}-\kappa \mathrm{B})$ activation, inflammation, and apoptosis $[13,14]$. The patients with chronic neurodegenerative symptoms like depression and apathy are for the most part treated with drugs that elevate biogenic amine levels. This common therapeutic strategy was believed to be responsible for the generation of neurotoxic aldehydes and enhanced oxidative stress which in turn further increases the biogenic amine turnover. The exploratory examinations likewise uncovered this last condition influencing and accelerating the course of neurodegeneration. Truth be told, the in vivo findings from chronic, unpredictable stress-induced depression models of mice prompted that the depression formation was strongly emphatically connected with the increased activities of MAOs and malondialdehyde (MDA) amounts and diminished glutathione levels, glutathione reductase, and glutathione peroxidase activities in the brain [15-17]. In a current report by Czarny et al. [18], it was accounted that elevated levels of reactive oxygen and nitrogen species (ROS and RNS) caused oxidative DNA damage in depressed patients. It is well known that chronic oxidative stress due to ROS and RNS production has a huge potential to drive carcinogenesis by altering the expression of cancerrelated genes causing mutation and transformation. Concordantly, it was discovered that gastric cancer patients with depression are under elevated levels of oxidative stress conditions that are accompanied by the dysfunction of numerous protooncogenes $[19,20]$.

Herbal therapies may be a fascinating and successful option in depression treatment, since a large number of herbal preparations have demonstrated psychotherapeutic activities. The search for new pharmacotherapy from medicinal herbs and constituents isolated from plant extracts for psychiatric disorders, including depression, has advanced expressively over the previous decade [21]. For instance, a flavonoid-rich fraction obtained from the seed extract of Monodora tenuifolia was able to do altogether to decrease behavioral alterations in forced-swim stressed rats and in addition exert protective effects against induced oxidative stress, supporting its antidepressant effect [22]. In another investigation, the methanolic extract from the species Byrsonima crassifolia (L.) Kunth (Malpighiaceae) uncovered antidepressant activity in the forced swimming test and the antioxidant flavonoids rutin, quercetin, and hesperidin perhaps are engaged with the antidepressant effects of $B$. crassifolia (L.) Kunth [23-26]. Flavonoids are a broad class of secondary metabolites copious in plants and different foods. They have been distinguished in an assortment of a variety of fruits and vegetables and confer color, flavor, and aroma, as well as nutritional and health benefits. Polyphenol flavonoids are the most effective functional ingredients with biological activities. Many flavonoids possess antioxidant and antidepressant activities $[10,24,25]$. It is widely reported that oxidative stress assumes a critical part in the development of various diseases [27], including psychopharmacological disorders [28]. Indeed, the connection between oxidative stress and depression has been studied and discussed in some reviews [28-31]. Accordingly, this review provides a detailed overview of the current state of knowledge about the antidepressant activities of flavonoids, as well as their relationship with oxidative stress.

\section{Methodology}

The search was conducted in the scientific database PubMed, focusing on works published during the last six years (January 2011 to December 2016). The data were selected using the following terms: "flavonoid" and "antidepressant" as well as the names of experimental models of depression in animals such as "Forced Swim Test" and "Tail Suspension Test" and "Oxidative Stress."

\section{Results and Discussion}

3.1. Flavonoids and BDNF Expression. BDNF is a neurotrophin expressed in the brain and participates in a range of intracellular signaling processes, neuronal protection and survival, axonal and dendritic morphology and synaptic plasticity [32]. It has been documented that BDNF is involved in a number of neuropsychiatric disorders such as affective disorders, schizophrenia, addiction, eating disorders, and neurodevelopmental disorders [33]. Decreased levels of BDNF are among the most frequently validated biomarkers of depressive disorder [32]. Importantly, reduced BDNF levels have been reported in postmortem brain samples from $\mathrm{AD}$ patients [34].

Hesperidin (1), a natural flavanone glycoside predominant in citrus fruits, has been accounted with useful therapeutic properties such as antidiabetic [35], antioxidant [36], neuroprotective [37], and anticancer [38]. El-Marasy et al. [39] reported the antidepressant effect of hesperidin in streptozotocin-induced diabetic rats (Table 1). The outcome of the study indicated that the effects of hesperidin are mediated at least in part, via its modulatory effect on hyperglycemia, its antioxidant and anti-inflammatory activities, alteration of BDNF levels, and activation of the brain's monoaminergic system. Furthermore, Donato et al. [40] observed that chronic administration of hesperidin resulted in an increase in hippocampal BDNF levels. These authors concluded that the antidepressant effect of hesperidin is mediated by inhibition of L-arginine-NO-cGMP pathway and by an increase of the BDNF levels in the hippocampus. In another examination, $\mathrm{Li}$ et al. [41] explored the antidepressant-like mechanism of hesperidin in mice exposed to chronic mild stress (CMS). The obtained results showed the ability of hesperidin to ameliorate the reduction of sucrose preference and reverse the augmented immobility 


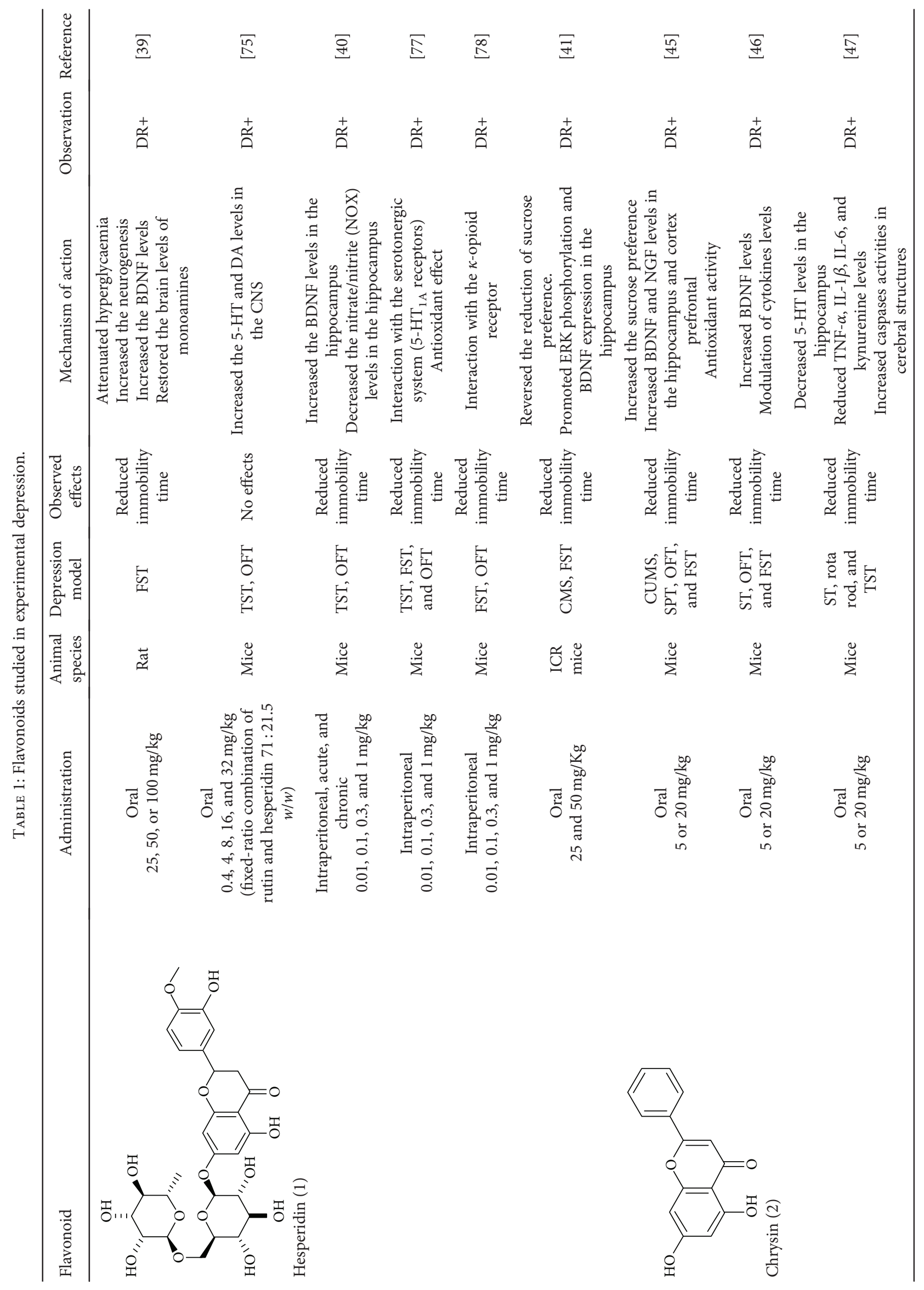




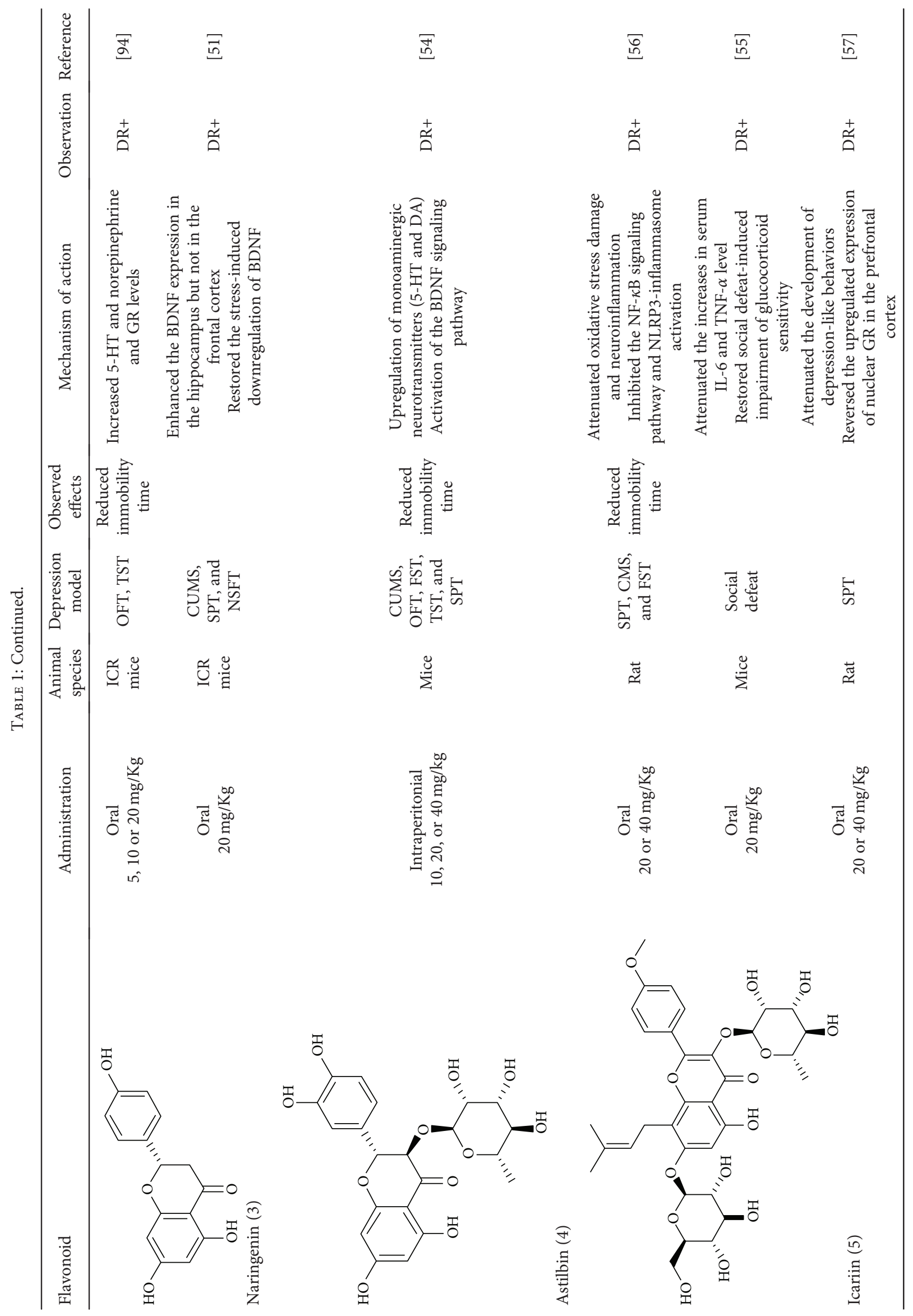




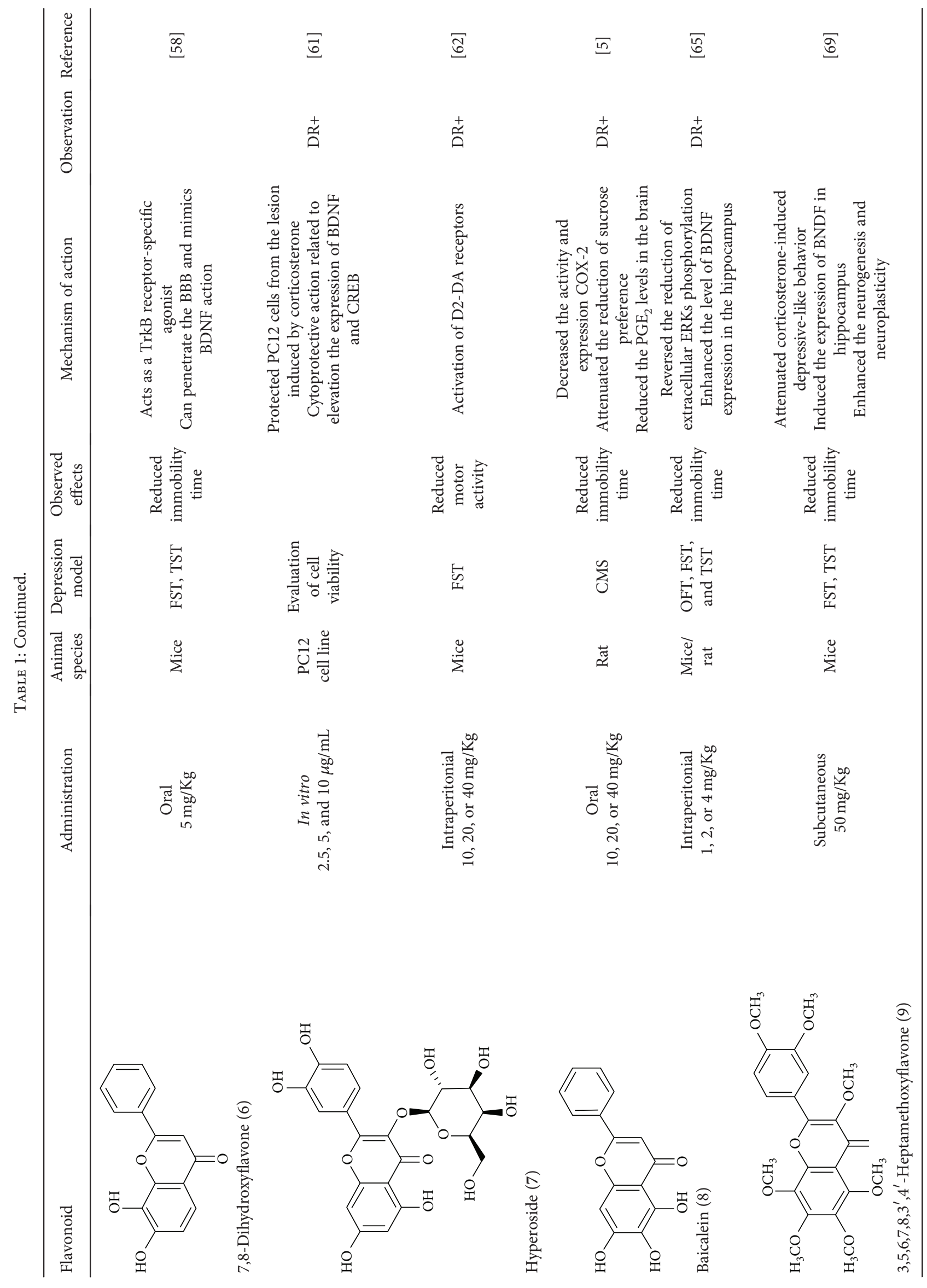




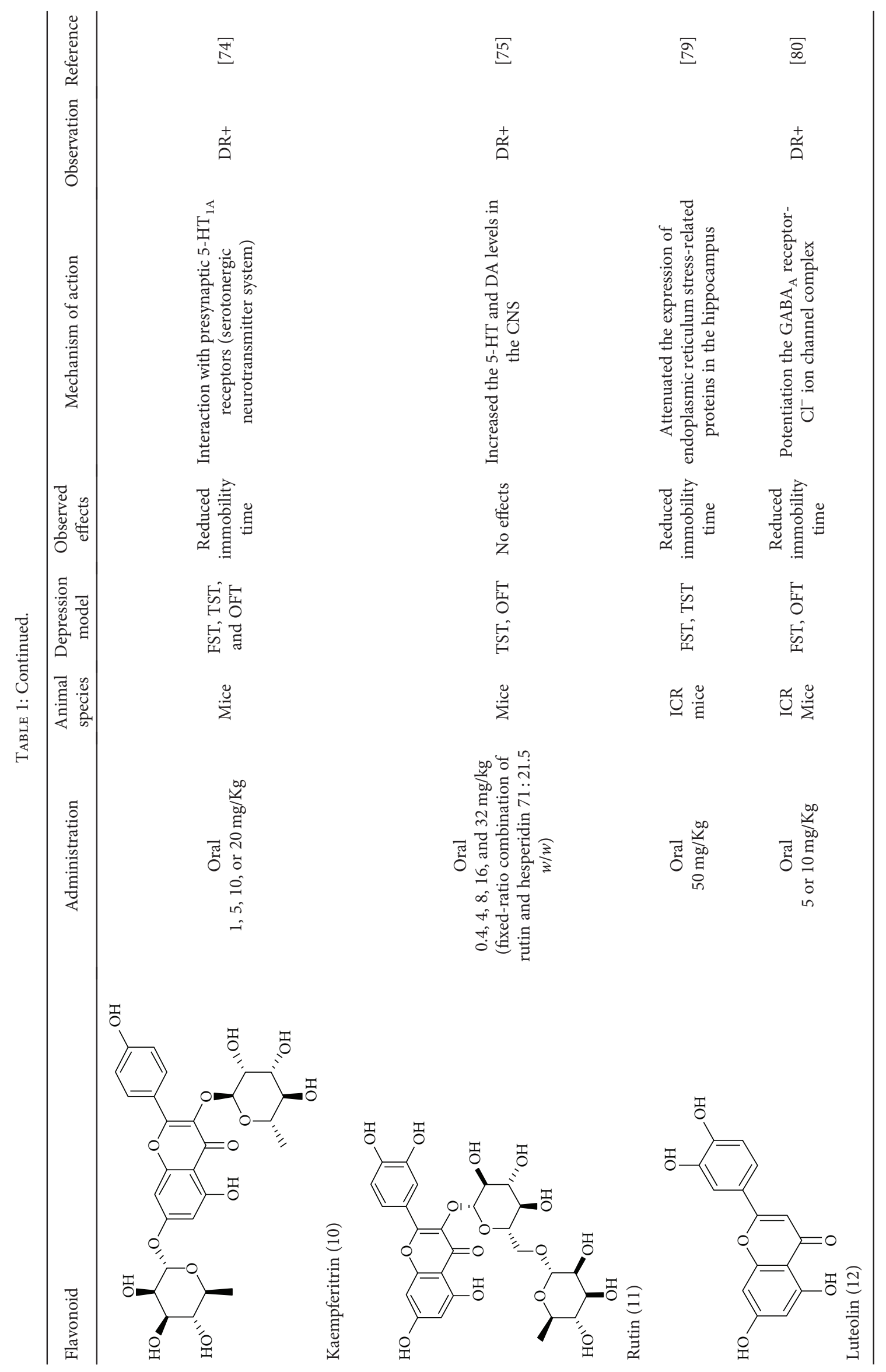




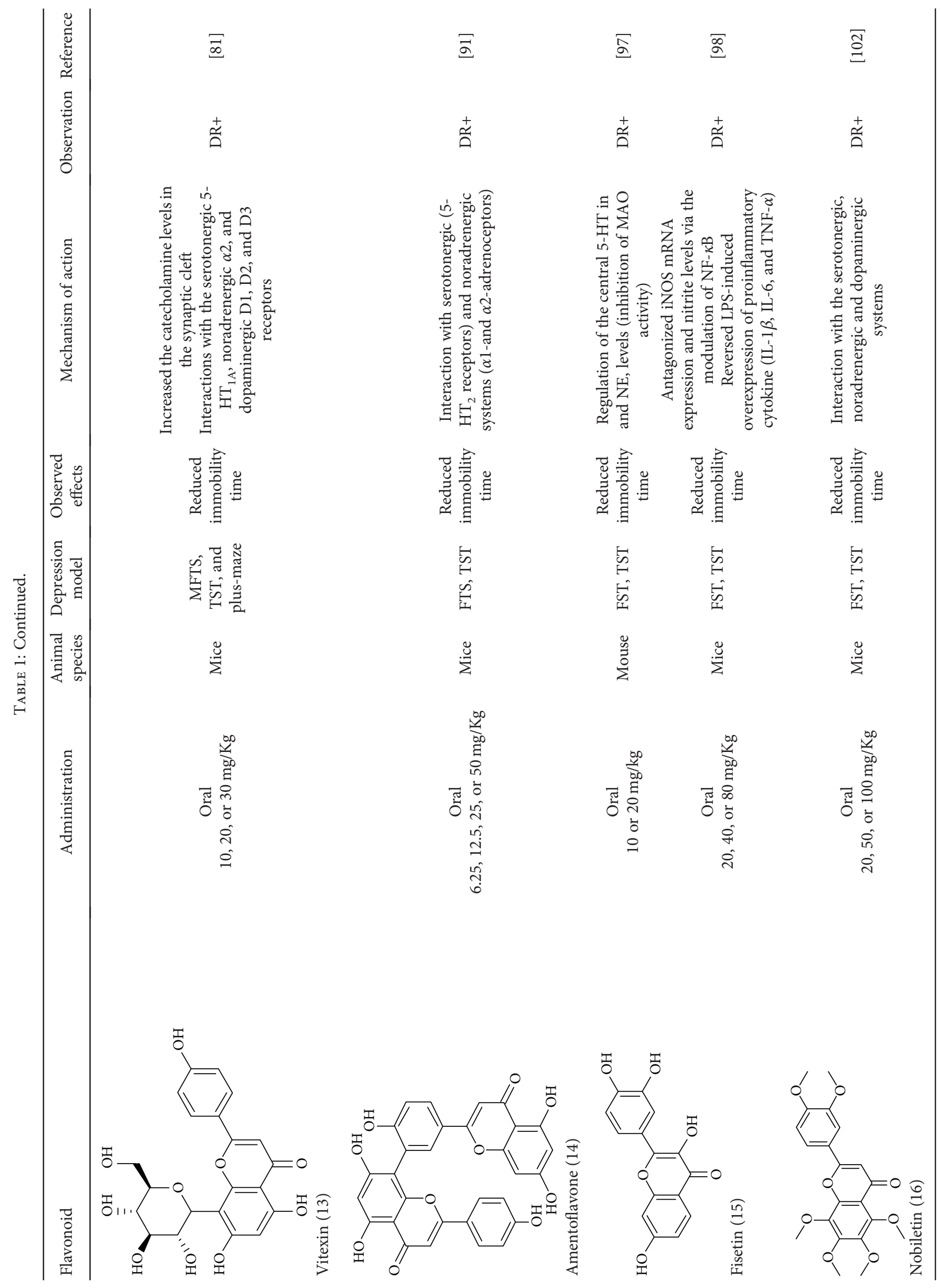




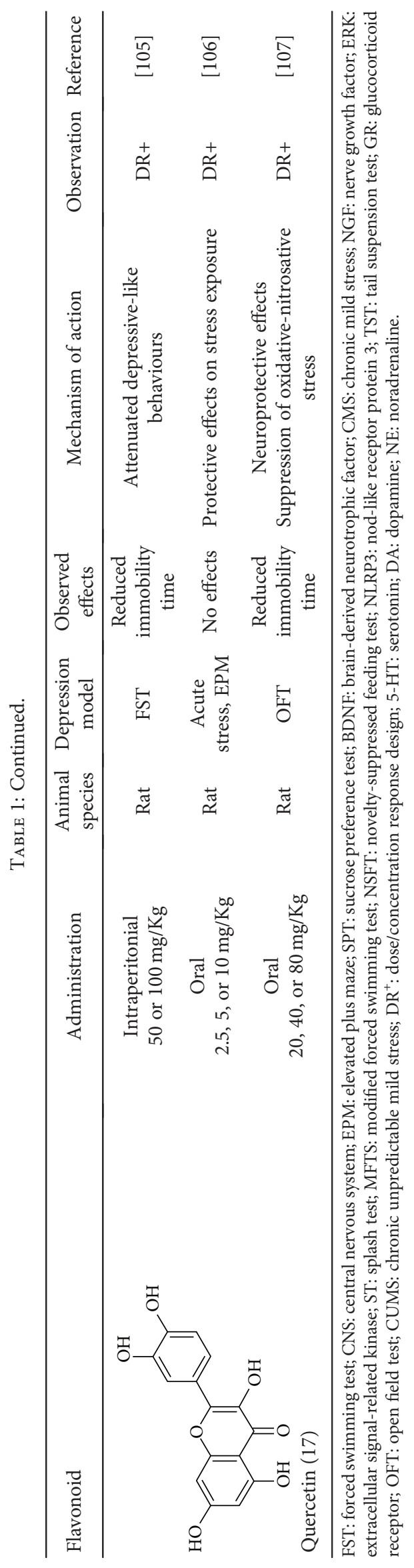




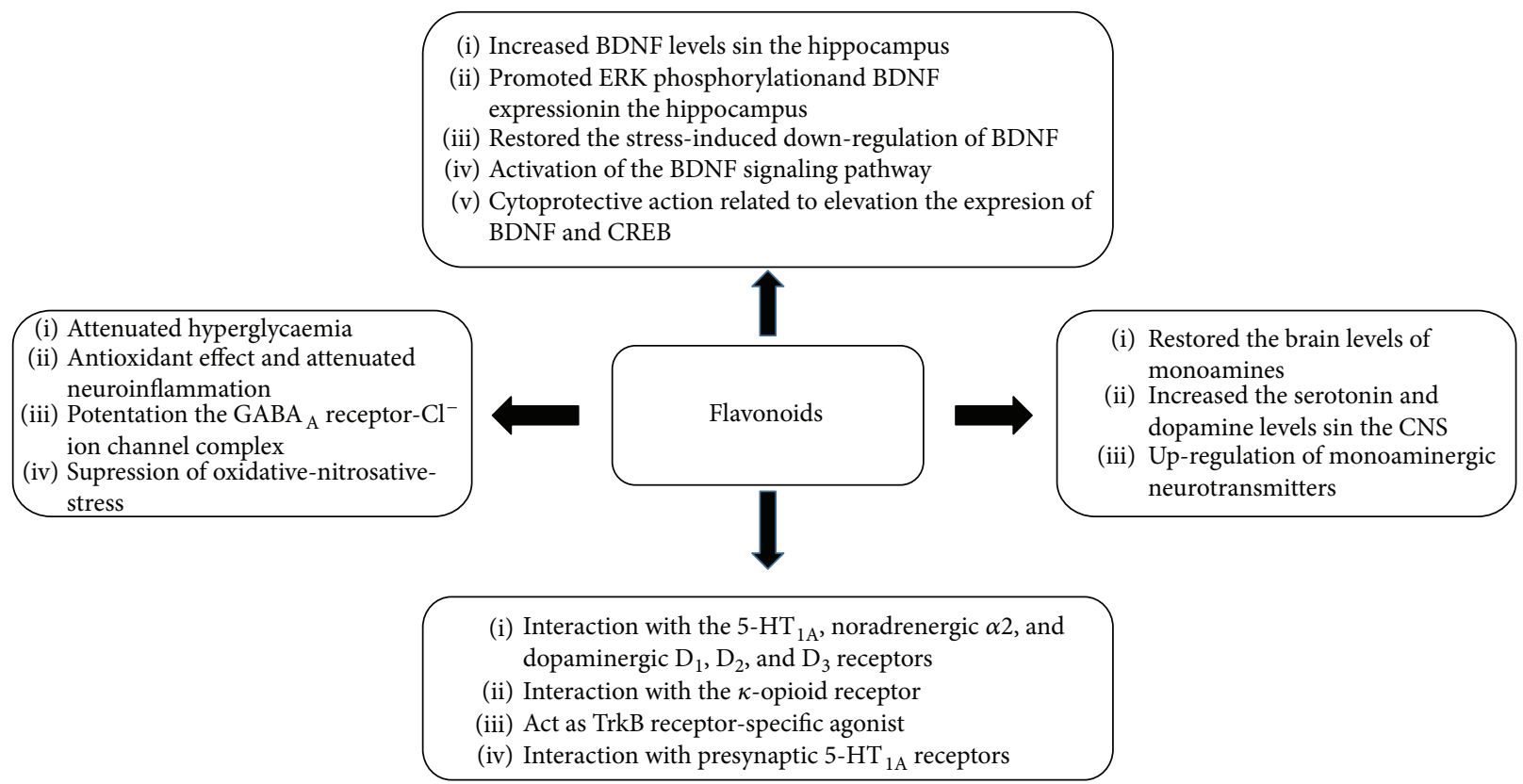

Figure 1: Possible mechanism of action of flavonoids with antidepressant activity.

time induced by CMS. All these information endorse the antidepressant effect of hesperidin and suggest that extracellular signal-regulated kinase- (ERK-) BDNF signaling pathway is involved in the antidepressant-like activity of this flavanone.

Chrysin (2), a natural flavonoid predominant in bee propolis, honey, and several plants, possesses multiple biological activities such as anti-inflammatory, antineoplastic, hypolipidemic, and antioxidant [42-44]. In addition, Filho et al. [45] revealed the antidepressant effect of chrysin in mice subjected to chronic unpredictable mild stress (Table 1 ). The authors proposed that upregulation of BDNF levels in the hippocampus and prefrontal cortex of stressed mice may be associated with the antidepressant effects of chrysin. In another study done by the same research group members [46], they showed that the treatment with chrysin caused the attenuation of depressive-like behavior and hippocampal changes in olfactory bulbectomized mice, reinforcing that BDNF plays an important role in the antidepressant effect of this flavonoid. Further, Filho et al. [47] likewise analyzed the neurochemical parameters correlated with the antidepressant property of chrysin in mice exposed to unpredictable chronic stress. The authors suggested an association existing between the antidepressant-like action of chrysin and the proinflammatory cytokines synthesis, 5-hydroxytryptamine metabolism, kynurenine pathway, and caspases activities.

Naringenin (3), a dietary flavonoid prevalent in the peels of citrus fruit, has various biological actions such as a cognitive enhancer [48] and inhibits monoamine oxidase activity [49] and neuroprotection [50]. Likewise, naringenin was found to display antidepressant effects [51]. The authors inferred that naringenin treatment can suppress neuroendocrine signaling and stimulate monoamines, which bring about upregulation of BDNF in the mice hippocampus.
Astilbin (4), a natural flavonoid heteroside displayed in the plants of Smilax or Hypericum perforatum L., has different pharmacological actions such as antioxidant, free radical scavenging, and anti-inflammatory function [52, 53]. Lv et al. [54] detailed additionally about the antidepressant effect of astilbin. They suggested that the effects of astilbin observed in experimental mice of depression are mediated by upregulation of the BDNF signal pathway and monoaminergic neurotransmitters discharge in the mice cortex.

Icariin (5) is a major bioactive compound from the species Herba Epimedii (Epimedium brevicornum Maxim), a traditional Chinese medicinal herb, used for centuries for treating various conditions including depression [55]. Among 19 metabolites originated of icariin, icariin has been found to possess neuroprotective potential [55]. Wu et al. [55] reported that icaritin is a novel antidepressant and partly restored social defeat-induced impairment of glucocorticoid sensitivity and hypothalamic-pituitary-adrenal (HPA) axis hyperactivity. These effects are at least partially attributed to normalization of the glucocorticoid receptor function and increases in BDNF expression. In addition, Liu et al. [56] also reported that icariin exerted an antidepressant effect in an unpredictable chronic mild stress model of depression in rats and is associated with the regulation of hippocampal neuroinflammation. In another study, Wei et al. [57] investigated the effects of icariin treatment in a model of depression in rats induced by unpredictable chronic mild stress. The obtained results suggest the therapeutic efficacy of icariin as a potential antidepressant. Furthermore, the antidepressant activity of this flavonoid heteroside occurs via different targets in both the hippocampus and prefrontal cortex.

7,8-Dihydroxyflavone (6) acts as a TrkB receptor-specific agonist and can mimic BDNF action. Also, it demonstrated therapeutic efficacy in animal models of various neurological diseases [58] such as Parkinson's disease, stroke [59], and 
depression [60]. Liu et al. [58] reported that 7,8-dihydroxyflavone can penetrate the brain-blood barrier (BBB) and mimics BDNF action. Also, the authors reported that this compound poses more prominent physiological activities than other reported peptide mimetics or small molecules, supporting the fact that 7,8-dihydroxyflavone is a superior compound with oral bioavailability for TrkB agonist drug development.

Hyperoside (7) is a natural flavonoid isolated from Apocynum venetum $\mathrm{L}$. leaves [61]. Zheng et al. [61] reported that hyperoside possesses antidepressant effects via cytoprotective action related to the elevation of the expression of BDNF and CREB through the signal pathway AC-CAMP-CREB within the PC12 cell line. In addition, Haas et al. [62] concluded that this flavonoid heteroside, extracted from the crude extract of Hypericum caprifoliatum Cham. \& Schltdl. (Guttiferae), presented a depressing effect on the central nervous system (CNS) and either an antidepressant effect in rodents mediated by the activation of D2-DA receptors.

Baicalein (8) is one of the most active flavonoids found in the dry roots of Scutellaria baicalensis Georgi. It has been reported that baicalein can get across the BBB [63]. Also, various studies have indicated that baicalein has proved to be a superior free radical scavenger and xanthine oxidase inhibitor $[63,64]$. Xiong et al. [65] reported that this flavone exhibited antidepressant effects. In addition, baicalein reversed the reduction of ERK phosphorylation and the level of BDNF expression in the hippocampus of chronic mild stress model rats. These results suggest that baicalein produces an antidepressant-like effect, and this effect is at least partly mediated by hippocampal ERK-mediated neurotrophic action. Furthermore, Li et al. [66] suggested that baicalein could prevent the chronic mild stress-induced depressivelike behavior through the inhibition of cyclooxygenase- 2 in rat brain and subsequently resulted in a reduction of prostaglandin $\mathrm{E}_{2}$ levels in the brain.

$3,5,6,7,8,3^{\prime}, 4^{\prime}$-Heptamethoxyflavone (9) is a polymethoxyflavone found in several citrus fruits [67]. This polymethoxyflavone possesses several biological activities, including anti-inflammatory, neuroprotective, [68] and the immunomodulatory function [67]. In a study performed by Sawamoto et al. [69], these authors suggested that the $3,5,6,7,8,3^{\prime}, 4^{\prime}$-heptamethoxyflavone exerts antidepressant activity by inducing the expression of BDNF. This flavone improved corticosterone-induced depression-like behavior and repaired BDNF expression, neurogenesis, and neuroplasticity in the hippocampus.

3.2. Flavonoids and Monoaminergic Systems. The monoamine theory of depression states that depression is associated with a decrease in monoamine levels in the synaptic cleft, namely, of the catecholamine $\mathrm{NE}$ and of the indoleamine 5-HT [70]. The main biochemical causes of depression are metabolic disorders of monoamine neurotransmitters that are involved in NE, 5-HT, and DA signaling $[5,10]$. Moreover, in many depressed patients, the impairment of the function of the HPA axis was noticed [71]. It has been reported that many flavonoids possess antioxidant, anti-inflammatory, and antidepressant activities in animal studies [72, 73].

Kaempferitrin (10) is the main secondary metabolite extracted from the Justicia spicigera Schltdl. (Asteraceae) plant. It has been documented that this plant is used for its analgesic, antidiabetic, anti-inflammatory, and antiseizure potential, as well as a tonic [74]. Cassani et al. [74] reported that kaempferitrin exhibited antidepressant effects in two behavior models in mice. In addition, its effect could be related to serotonergic neurotransmitter system action, mainly through its interaction with presynaptic $5-\mathrm{HT}_{1 \mathrm{~A}}$ receptors. Also, the authors suggested the involvement of the HPA axis in the antidepressant-like effect of kaempferitrin.

The antidepressant effect of the Hemerocallis citrina Baroni is mediated by the contributions of flavonoids, especially rutin (11) and hesperidin (1) [75]. Its antidepressant effects are due to the interaction with serotonergic, noradrenergic, and dopaminergic systems [76]. The antidepressant effect of hesperidin depends on its interaction with serotonergic $5-\mathrm{HT}_{1 \mathrm{~A}}$ receptors [77]. The aforementioned mechanism of hesperidin action is also supported by Souza et al. [77] studies by interaction with the serotonergic $5-\mathrm{HT}_{1 \mathrm{~A}}$ receptors. Filho et al. [78] also reported the antidepressant effect of hesperidin in a mice model of anxiety, through its interaction with $\kappa$-opioid receptors, but not with the $\delta$-opioid, $\mu$-opioid, or adenosinergic receptors.

Luteolin (12) is a common flavonoid with various pharmacological actions such as antioxidant, anticancer, memory-enhancing, and anxiolytic, indicating that luteolin could easily penetrate the BBB [79]. De la Peña et al. [80] reported that luteolin mediates the antidepressant effects of Cirsium japonicum Fisch. ex DC., possibly by potentiation of the $\mathrm{GABA}_{\mathrm{A}}$ receptor-Cl-ion channel complex. Also, Ishisaka et al. [79] have shown that luteolin attenuated the expression of endoplasmic reticulum stress-related proteins in the hippocampus of corticosterone-treated depression model mice.

Vitexin (13) is a flavone glycoside present in foodstuffs and nutraceuticals [81]. It has been shown that vitexin has multiple pharmacological effects such as inhibitory effects on adipogenesis [82], platelet aggregation [83], $\alpha$-glucosidase [84] and urease [85], and antitumor/antimetastatic [86], antioxidant [87], anti-inflammatory, [88] and peripheral analgesic [89] activities. Among plants, Passiflora incarnata L. (Passifloraceae) have been found to be the main source of vitexin, with significant effects on the CNS, including anxiolytic effects. Can et al. [81] reported that vitexin possess antidepressant effect mediated by an increase in catecholamine levels in the synaptic cleft as well as by interactions with the serotonergic $5-\mathrm{HT}_{1 \mathrm{~A}}$, noradrenergic $\alpha_{2}$, and dopaminergic $\mathrm{D}_{1}, \mathrm{D}_{2}$, and $\mathrm{D}_{3}$ receptors.

Amentoflavone (14) is a natural flavonoid with many biological properties such as antioxidative, anti-inflammatory, and neuroprotective effects [90]. Ishola et al. [91] reported the antidepressant and anxiolytic effects of amentoflavone isolated from Cnestis ferruginea Vahl ex DC. in mice. The authors concluded that amentoflavone produces its antidepressant effects through interactions with the $5-\mathrm{HT}_{2}$ receptor 
and $\alpha 1$ - and $\alpha 2$-adrenoceptors while the anxiolytic effect involved the ionotropic GABA receptor.

Naringenin (3) is a flavanone found in high amounts in the peels of citrus fruits with several biological effects such as neuroprotective [92] and monoamine oxidase inhibitory activity [34]. Moreover, naringenin exhibited antidepressant effects via monoaminergic systems [93]. Yi et al. [94] reported the antidepressant-like behavioral, neurochemical, and neuroendocrine effects of naringenin in the mouse repeated the tail suspension test. The authors concluded that the antidepressant effects of naringenin may be mediated by an interaction with neuroendocrine and neurochemical systems.

Fisetin (15) is a natural flavonoid found especially in strawberries and other fruits or vegetables. This flavonoid has various biological activities, including antioxidant, antiinflammatory, and neuroprotective effects [95, 96]. Zhen et al. [97] reported that the antidepressant-like effect of fisetin involves the serotonergic and noradrenergic systems. The authors concluded that the positive effects of fisetin on the depressive response are likely mediated via the central serotonergic and noradrenergic system by inhibiting the monoamine oxidase enzyme activity. In another study, $\mathrm{Yu}$ et al. [98] evaluated the ability of fisetin to modulate depressive-like behavior in a lipopolysaccharide- (LPS-) induced acute neuroinflammation model. The authors concluded that fisetin is a potential candidate for clinical mental disorder therapy since it can correct depressive-like behavior in LPS-induced depression in mice model.

Nobiletin (16) is a dietary flavonoid abundant in the peels of citrus with many potential health benefits. It has been reported that nobiletin exerts protective effects on $\beta$-amyloid peptide-induced impairment of learning ability [99], improved the memory impairment, reduced the $\beta$-amyloid peptide levels [100], and had neuroprotective effects on ischemia-induced neuronal death in the hippocampal CA1 region [101]. Yi et al. [102] reported the involvement of monoaminergic systems in the antidepressant-like effect of nobiletin. The authors concluded that the antidepressantlike effect of nobiletin seems to be mediated by an interaction with the serotonergic (5- $\mathrm{HT}_{1 \mathrm{~A}}$ and $5-\mathrm{HT}_{2}$ receptors), noradrenergic ( $\alpha 1$-adrenoceptor), and dopaminergic $\left(D_{1}\right.$ and $D_{2}$ receptors) systems.

Quercetin (17) is a dietary flavonoid presented in high amount in onion, apple, broccoli, and wine, as well as plants like Ginkgo biloba L. and green tea [103]. It has been reported that quercetin is a powerful radical scavenger flavonol and so that it fortifies the antioxidant defense system [104]. In addition, quercetin increase 5-HT and norepinephrine availability in synaptic cleft that seems to be dysregulated in depression. Demir et al. [105] reported antidepressant-like effects of quercetin in diabetic rats (Table 1). The authors concluded that quercetin may be considered as a partially useful supplement for the treatment of diabetic depression, and the antidepressant-like properties of quercetin seem to be independent of the HPA axis. Furthermore, Scheggi et al. [106] reported antidepressant activity of Hypericum perforatum L. (Hypericaceae) related to the flavonoid components of this species including quercetin. Also, Rinwa and Kumar [107] have shown that quercetin suppresses the microglial neuroinflammatory response and induces the antidepressant-like effect in olfactory bulbectomized rats.

3.3. Antioxidant Effect of Antidepressant Flavonoids. Contemporary endeavours are being given to explore novel natural remedies for better positive effect with no or less toxic effects alternatives to conventional antidepressants. Despite not being fully studied or understood, naturally occurring flavonoids have demonstrated less or more neuroprotective activities. The neuroprotective mechanisms of antidepressant effects remain to stay vague, in spite of the fact that it is proposed that flavonoids generally exert their antidepressantlike effects via altering behavior, cytokine levels, oxidative stress, and energy metabolism parameters. In addition to antioxidative action, each flavonoid follows its idiocratical one or more different pathways from these general routes against advancement and progression of depression including prevention of mitochondrial membrane potential dissipation, agonizing GABA-benzodiazepine receptors interaction with $\kappa$-opioid receptors and kynurenine pathway (KP), acetylcholinesterase activity regulation, helping to maintain brain plasticity, inhibition of L-arginine-NO, extracellular signal-related kinase (ERK) $1 / 2$ and AKT phosphorylation pathways, modulation of intracellular calcium overload and $\mathrm{K}^{+}$channels, downregulation of Bax, caspases 3 and 9, and cytochrome C (Cyt-C) protein expression, and upregulation of $\mathrm{Bcl}$ protein expression were also afforded to positive impacts of flavonoids in the treatment depression [108-112].

Due to their serious side effects of the current MAO inhibitors and the urgent need for novel ones, natural products have been considered as alluring focuses for pharmacologists. Exceptionally, a few reports obviously settled higher effectiveness by flavonoids compared to placebo intake and a similar activity was observed when comparing to several antidepressant drugs. Among these flavonoids that display antidepressive-like activity such as hesperidin (1), naringenin (3), quercetin (17), and astilbin (4) have been appeared to diminish depressive symptoms in animals experimental trials or in vitro models (Figure 1), mainly for the most part by means of the (i) inhibiting monoamine oxidases (MAOs) and (ii) altering oxidative/antioxidant defenses and/or (iii) inflammatory responses [113-115].

Several flavonoids have been appeared to avert against neurodegenerative disorders and depressive insults. However, limited studies are recorded in the literature with respect to the neuroprotective mechanisms of these naturally occurring compounds more particularly in the treatment of depressive disorders. From the literature scanning, it was clearly comprehended that the conceivable mode of action of flavonoids included quenching free radical elements and the stimulation of internal antioxidant enzymes mainly. In fact, hesperidin led to the decrease of ROS generation, enhances of superoxide dismutase (SOD) and glutathione (GSH) levels, and reduced MDA formation in cultured different human cell lines including $\mathrm{HaCaT}$ and ARPE-19 cells [116-118]. While amentoflavone (14) displays inhibitory consequences on the productions of superoxide anion and 
total reactive oxygen species (ROS) [119] and neuroprotective activity by means of restoration of the reduced superoxide dismutase (SOD) activity, glutathione reductase (GR) activity, and glutathione content induced by glutamate [120]. Vitexin (13) is another flavonoid that shows neuroprotective action demonstrated in studies. In the mechanism of action, suppression of isoflurane-induced caspase- 3 activation and increased $\beta$-secretase 1 levels in PC12 cells was proposed. It has also been reported to decrease the levels of isoflurane-induced cytosolic calcium and reactive oxygen species [121]. Likewise, cellular ROS production induced by several oxidative damaging agents was attenuated by pretreatment with chrysin (2) [122], naringenin (3) [123], astilbin (4) [53], icariin (5) [124], 7,8-dihydroxyflavone (6) [125], hyperoside (7) [126], baicalein (8) [127], rutin (11) [128], luteolin (12) [129], fisetin (15) [130], nobiletin (16) [131], kaempferitrin (10) [132], and quercetin (17) [133].

Another revealed the antioxidative mechanism of action of flavonoids was through the chelation of transition metal elements. Then, these natural compounds enabled metals to chelate or binds to metal ions in humans and animals to block them being accessible to oxidation [116]. Now, hesperidin (1) [36], naringenin (3) [123], astilbin (4) [134], luteolin (12) [135], and quercetin (17) [136] appeared to chelate metal ions such as iron, copper, and zinc in showing their antiradical properties. Notwithstanding free radicals scavenging and chelating of metal ions, several flavonoids, including hesperidin (1), astilbin (4), luteolin (12), baicalein (8), and quercetin (17), played key roles in inhibiting free radical generating enzymes such as myeloperoxidase, xanthine oxidase, lipoxygenase, microsomal monooxygenase, and NADPH oxidase [137-143]. The polymethoxyflavones nobiletin (16) and $3,5,6,7,8,3^{\prime}, 4^{\prime}$-heptamethoxyflavone (9), found in young fruits of Citrus unshiu Marc., inhibit NO production, LPS-induced iNOS protein, and mRNA expression by NF- $\kappa \mathrm{B}$ activation and $\mathrm{p} 38$-mitogen-activated protein kinase (MAPK) phosphorylation. Interestingly, the young citrus fruit demonstrated a neuroprotective effect by delaying neurodegeneration in hippocampal CA1 neurons of the Mongolian gerbil after global ischemia [144]. It is revealed that depression is closely associated with altered cellular resilience, selective structural changes, and neuronal atrophy of the hippocampus $[145,146]$. Therefore, a possible reversal of these changes structures by constituents of the plant, such as antioxidant flavonoids nobiletin

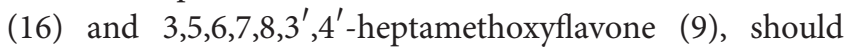
be an interesting way to treat this behavioral disorder. Truth be told, it has as of late been exhibited that orally administered $3,5,6,7,8,3^{\prime}, 4^{\prime}$-heptamethoxyflavone (9) is beneficial for the upregulation of BDNF in the hippocampus via the ERK1/2/MAP system. These information ought to be identified with the antidepressant effects of this compound [147].

Hyperoside (7) inhibits 13-HPODE-induced ROS production in PC-12 cells. This compound is found in Apocynum venetum $\mathrm{L}$. which likewise has antidepressant and antioxidant activity. Hyperoside (7) is one of the constituents in the extract of this plant that contribute to these activities.
Whereas oxidative stress may be associated with the advancement of depression, both extract and compound 7 must have protective action against oxidative stress in nerve cells [148].

Once more, this class of compounds might act as antidepressant agents endowed with multiple mechanisms of action in the CNS, increasing central neurotransmission, limiting the reabsorption of bioamines by synaptosomes, and modulating the neuroendocrine and $\mathrm{GABA}_{\mathrm{A}}$ systems [149]. Curiously, support with several flavonoids strengthened the pharmacokinetic efficacy of many medications for depression. The flavonoids hesperidin (1) and naringenin (3) enhanced the area under the curve (AUC), maximum plasma concentration $\left(C_{\max }\right)$, and elimination half-life $\left(t_{1 / 2}\right)$ of rasagiline, a selective monoamine oxidase- $\mathrm{B}$ inhibitor, with a concomitant reduction in clearance $(\mathrm{CL} / \mathrm{F})$ in both single and multiple dose studies [150], while quercetin (17) affects glutamatergic neurotransmission in rat brain [151] evidencing the action of this compound in the glutamateric framework.

\section{Conclusions}

Considering that oxidative stress is unequivocally associated with the advancement of depression, the reported data suggest that the utilization of these flavonoids may help in reducing the symptoms of depression, notably via supplementation of dietary flavonoids in which they are significantly related with the minimization of depression risk due to their great antioxidative natures. Regrettably, advanced investigations are needed to fully understand the mode of action to neuroprotection, biotransformation of their metabolites in the body, and interaction properties with receptors related to depression.

\section{Conflicts of Interest}

The authors declare no conflicts of interest.

\section{Acknowledgments}

This research was supported by the Conselho Nacional de Desenvolvimento Científico e Tecnológico (CNPq) and Coordenação de Aperfeiçoamento de Pessoal de Nível Superior (CAPES).

\section{References}

[1] Z. Guo, X. Liu, H. Hou, F. Wei, J. Liu, and X. Chen, "Abnormal degree centrality in Alzheimer's disease patients with depression: a resting-state functional magnetic resonance imaging study," Experimental Gerontology, vol. 79, pp. 6166, 2016

[2] S. Chi, C. Wang, T. Jiang, X. C. Zhu, J. T. Yu, and L. Tan, "The prevalence of depression in Alzheimer's disease: a systematic review and meta-analysis," Current Alzheimer Research, vol. 12, no. 2, pp. 189-198, 2015.

[3] M. Naudin and B. Atanasova, "Olfactory markers of depression and Alzheimer's disease," Neuroscience \& Biobehavioral Reviews, vol. 45, pp. 262-270, 2014. 
[4] V. Krishnan and E. J. Nestler, "The molecular neurobiology of depression," Nature, vol. 455, no. 7215, pp. 894-902, 2008.

[5] Y. C. Li, J. D. Shen, J. Li, R. Wang, S. Jiao, and L. T. Yi, "Chronic treatment with baicalin prevents the chronic mild stress-induced depressive-like behavior: involving the inhibition of cyclooxygenase-2 in rat brain," Progress in NeuroPsychopharmacology and Biological Psychiatry, vol. 40, pp. 138-143, 2013.

[6] S. Wuwongse, R. C. C. Chang, and A. C. K. Law, "The putative neurodegenerative links between depression and Alzheimer's disease," Progress in Neurobiology, vol. 91, no. 4, pp. 362-375, 2010.

[7] P. J. Seignourel, M. E. Kunik, L. Snow, N. Wilson, and M. Stanley, "Anxiety in dementia: a critical review," Clinical Psychology Review, vol. 28, no. 7, pp. 1071-1082, 2008.

[8] S. E. Starkstein, R. Mizrahi, and B. D. Power, "Depression in Alzheimer's disease: phenomenology, clinical correlates and treatment," International Review of Psychiatry, vol. 20, no. 4, pp. 382-388, 2008.

[9] S. Ammendola and C. Kornreich, "Are antidepressants really effective?," Revue Medicale de Bruxelles, vol. 36, no. 5, pp. 421-429, 2015.

[10] L. P. Guan and B. Y. Liu, "Antidepressant-like effects and mechanisms of flavonoids and related analogues," European Journal of Medicinal Chemistry, vol. 121, pp. 47-57, 2016.

[11] M. E. Thase, "Evaluating antidepressant therapies: remission as the optimal outcome," The Journal of Clinical Psychiatry, vol. 64, pp. 18-25, 2003.

[12] D. D. Mousseau and G. B. Baker, "Recent developments in the regulation of monoamine oxidase form and function: is the current model restricting our understanding of the breadth of contribution of monoamine oxidase to brain [dys]function?," Current Topics in Medicinal Chemistry, vol. 12, no. 20, pp. 2163-2176, 2012.

[13] X. Cao, L. Rui, P. R. Pennington et al., "Serine 209 resides within a putative $\mathrm{p} 38$ (MAPK) consensus motif and regulates monoamine oxidase-A activity," Journal of Neurochemistry, vol. 111, no. 1, pp. 101-110, 2009.

[14] C. S. Lam, J. J. Li, G. L. Tipoe, M. B. H. Youdim, and M. L. Fung, "Monoamine oxidase A upregulated by chronic intermittent hypoxia activates indoleamine 2,3-dioxygenase and neurodegeneration," PLoS One, vol. 12, no. 6, article e0177940, 2017.

[15] Q. Q. Mao, S. P. Ip, K. M. Ko, S. H. Tsai, Y. F. Xian, and C. T. Che, "Effects of peony glycosides on mice exposed to chronic unpredictable stress: further evidence for antidepressant-like activity," Journal of Ethnopharmacology, vol. 124, no. 2, pp. 316-320, 2009.

[16] A. E. S. El-Tarras, H. F. Attia, M. M. Soliman, M. A. El Awady, and A. A. Amin, "Neuroprotective effect of grape seed extract against cadmium toxicity in male albino rats," International Journal of Immunopathology and Pharmacology, vol. 29, no. 3, pp. 398-407, 2016.

[17] P. Riederer and T. Müller, "Use of monoamine oxidase inhibitors in chronic neurodegeneration," Expert Opinion on Drug Metabolism \& Toxicology, vol. 13, no. 2, pp. 233-240, 2017.

[18] P. Czarny, P. Wigner, P. Galecki, and T. Sliwinski, “The interplay between inflammation, oxidative stress, DNA damage, DNA repair and mitochondrial dysfunction in depression," Progress in Neuro-Psychopharmacology and Biological Psychiatry, vol. 80, Part C, pp. 309-321, 2018.
[19] T. Huang, F. Zhou, F. Wang-Johanning, K. Nan, and Y. Wei, "Depression accelerates the development of gastric cancer through reactive oxygen species-activated ABL1 (review)," Oncology Reports, vol. 36, no. 5, pp. 2435-2443, 2016.

[20] J. Kruk and H. Y. Aboul-Enein, "Reactive oxygen and nitrogen species in carcinogenesis: implications of oxidative stress on the progression and development of several cancer types," Mini Reviews in Medicinal Chemistry, vol. 17, no. 11, pp. 904-919, 2017.

[21] Z. J. Zhang, "Therapeutic effects of herbal extracts and constituents in animal models of psychiatric disorders," Life Sciences, vol. 75, no. 14, pp. 1659-1699, 2004.

[22] R. C. Ekeanyanwu and O. U. Njoku, "Flavonoid-rich fraction of the MonoMonodora tenuifolia seed extract attenuates behavioural alterations and oxidative damage in forcedswim stressed rats," Chinese Journal of Natural Medicines, vol. 13, no. 3, pp. 183-191, 2015.

[23] M. Herrera-Ruiz, A. Zamilpa, M. González-Cortazar et al., "Antidepressant effect and pharmacological evaluation of standardized extract of flavonoids from Byrsonima crassifolia," Phytomedicine, vol. 18, no. 14, pp. 1255-1261, 2011.

[24] J. Sun, H. Wang, B. Liu et al., "Rutin attenuates $\mathrm{H}_{2} \mathrm{O}_{2}$ induced oxidation damage and apoptosis in Leydig cells by activating PI3K/Akt signal pathways," Biomedicine \& Pharmacotherapy, vol. 88, pp. 500-506, 2017.

[25] S. Kanimozhi, P. Bhavani, and P. Subramanian, "Influence of the flavonoid, quercetin on antioxidant status, lipid peroxidation and histopathological changes in hyperammonemic rats," Indian Journal of Clinical Biochemistry, vol. 32, no. 3, pp. 275-284, 2017.

[26] A. Ahmadi and A. Shadboorestan, "Oxidative stress and cancer; the role of hesperidin, a citrus natural bioflavonoid, as a cancer chemoprotective agent," Nutrition and Cancer, vol. 68, no. 1, pp. 29-39, 2016.

[27] Z. Liu, T. Zhou, A. C. Ziegler, P. Dimitrion, and L. Zuo, "Oxidative stress in neurodegenerative diseases: from molecular mechanisms to clinical applications," Oxidative Medicine and Cellular Longevity, vol. 2017, Article ID 2525967, 11 pages, 2017.

[28] S. Salim, "Oxidative stress and the central nervous system," The Journal of Pharmacology and Experimental Therapeutics, vol. 360, no. 1, pp. 201-205, 2017.

[29] M. Vaváková, Z. Duračková, and J. Trebatická, “Markers of oxidative stress and neuroprogression in depression disorder," Oxidative Medicine and Cellular Longevity, vol. 2015, Article ID 898393, 12 pages, 2015.

[30] D. Filipović, N. Todorović, R. E. Bernardi, and P. Gass, "Oxidative and nitrosative stress pathways in the brain of socially isolated adult male rats demonstrating depressive- and anxiety-like symptoms," Brain Structure and Function, vol. 222, no. 1, pp. 1-20, 2017.

[31] P. K. Maurya, C. Noto, L. B. Rizzo et al., "The role of oxidative and nitrosative stress in accelerated aging and major depressive disorder," Progress in Neuro-Psychopharmacology and Biological Psychiatry, vol. 65, pp. 134-144, 2016.

[32] J. Pláteník, Z. Fišar, R. Buchal et al., "GSK3 $\beta$, CREB, and BDNF in peripheral blood of patients with Alzheimer's disease and depression," Progress in Neuro-Psychopharmacology and Biological Psychiatry, vol. 50, pp. 83-93, 2014.

[33] G. Y. Zheleznyakova, H. Cao, and H. B. Schiöth, "BDNF DNA methylation changes as a biomarker of psychiatric 
disorders: literature review and open access database analysis," Behavioral and Brain Functions, vol. 12, no. 1, p. 17, 2016.

[34] H. Tanila, "The role of BDNF in Alzheimer's disease," Neurobiology of Disease, vol. 97, Part B, pp. 114-118, 2017.

[35] S. T. Ahmad, W. Arjumand, S. Nafees et al., "Hesperidin alleviates acetaminophen induced toxicity in Wistar rats by abrogation of oxidative stress, apoptosis and inflammation," Toxicology Letters, vol. 208, no. 2, pp. 149-161, 2012.

[36] H.-L. Yang, S.-C. Chen, K. J. Senthil Kumar et al., “Antioxidant and anti-inflammatory potential of hesperetin metabolites obtained from hesperetin-administered rat serum: an ex vivo approach," Journal of Agricultural and Food Chemistry, vol. 60, no. 1, pp. 522-532, 2011.

[37] S. L. Hwang and G. C. Yen, "Neuroprotective effects of the citrus flavanones against $\mathrm{H}_{2} \mathrm{O}_{2}$-induced cytotoxicity in PC12 cells," Journal of Agricultural and Food Chemistry, vol. 56, no. 3, pp. 859-864, 2008.

[38] K. H. Lee, M. H. Yeh, S. T. Kao et al., "The inhibitory effect of hesperidin on tumor cell invasiveness occurs via suppression of activator protein 1 and nuclear factor-kappaB in human hepatocellular carcinoma cells," Toxicology Letters, vol. 194, no. 1-2, pp. 42-49, 2010.

[39] S. A. El-Marasy, H. M. I. Abdallah, S. M. El-Shenawy, A. S. ElKhatib, O. A. El-Shabrawy, and S. A. Kenawy, "Anti-depressant effect of hesperidin in diabetic rats," Canadian Journal of Physiology and Pharmacology, vol. 92, no. 11, pp. 945-952, 2014.

[40] F. Donato, M. G. de Gomes, A. T. R. Goes et al., "Hesperidin exerts antidepressant-like effects in acute and chronic treatments in mice: possible role of L-arginine-NO-cGMP pathway and BDNF levels," Brain Research Bulletin, vol. 104, pp. 19-26, 2014.

[41] C.-F. Li, S.-M. Chen, X.-M. Chen et al., "ERK-dependent brain-derived neurotrophic factor regulation by hesperidin in mice exposed to chronic mild stress," Brain Research Bulletin, vol. 124, pp. 40-47, 2016.

[42] H. Cho, C. W. Yun, W. K. Park et al., "Modulation of the activity of pro-inflammatory enzymes, COX-2 and iNOS, by chrysin derivatives," Pharmacological Research, vol. 49, no. 1, pp. 37-43, 2004.

[43] T. Lapidot, M. D. Walker, and J. Kanner, "Antioxidant and prooxidant effects of phenolics on pancreatic $\beta$-cells in vitro," Journal of Agricultural and Food Chemistry, vol. 50, no. 25, pp. 7220-7225, 2002.

[44] M. S. Zarzecki, S. M. Araujo, V. C. Bortolotto, M. T. de Paula, C. R. Jesse, and M. Prigol, "Hypolipidemic action of chrysin on triton WR-1339-induced hyperlipidemia in female C57BL/6 mice," Toxicology Reports, vol. 1, pp. 200-208, 2014.

[45] C. B. Filho, C. R. Jesse, F. Donato et al., "Chronic unpredictable mild stress decreases BDNF and NGF levels and $\mathrm{Na}^{+}, \mathrm{K}^{+}$ATPase activity in the hippocampus and prefrontal cortex of mice: antidepressant effect of chrysin," Neuroscience, vol. 289, pp. 367-380, 2015.

[46] C. B. Filho, C. R. Jesse, F. Donato et al., "Chrysin promotes attenuation of depressive-like behavior and hippocampal dysfunction resulting from olfactory bulbectomy in mice," Chemico-Biological Interactions, vol. 260, pp. 154-162, 2016.

[47] C. B. Filho, C. R. Jesse, F. Donato et al., "Neurochemical factors associated with the antidepressant-like effect of flavonoid chrysin in chronically stressed mice," European Journal of Pharmacology, vol. 791, pp. 284-296, 2016.

[48] T. Baluchnejadmojarad and M. Roghani, "Effect of naringenin on intracerebroventricular streptozotocin-induced cognitive deficits in rat: a behavioral analysis," Pharmacology, vol. 78, no. 4, pp. 193-197, 2006.

[49] H. T. Olsen, G. I. Stafford, J. van Staden, S. B. Christensen, and A. K. Jäger, "Isolation of the MAO-inhibitor naringenin from Mentha aquatica L," Journal of Ethnopharmacology, vol. 117, no. 3, pp. 500-502, 2008.

[50] V. P. Muthaiah, L. Venkitasamy, F. M. Michael, K. Chandrasekar, and S. Venkatachalam, "Neuroprotective role of naringenin on carbaryl induced neurotoxicity in mouse neuroblastoma cells," Journal of Pharmacology \& Pharmacotherapeutics, vol. 4, no. 3, pp. 192-197, 2013.

[51] L. T. Yi, B. B. Liu, J. Li et al., "BDNF signaling is necessary for the antidepressant-like effect of naringenin," Progress in Neuro-Psychopharmacology and Biological Psychiatry, vol. 48, pp. 135-141, 2014.

[52] A. Naqinezhad, S. Nabavi, S. Nabavi, and M. Ebrahimzadeh, "Antioxidant and antihemolytic activities of flavonoid rich fractions of Artemisia tschernieviana Besser," European Review for Medical and Pharmacological Sciences, vol. 16, Supplement 3, pp. 88-94, 2012.

[53] F. Petacci, S. S. Freitas, I. L. Brunetti, and N. M. Khalil, "Inhibition of peroxidase activity and scavenging of reactive oxygen species by astilbin isolated from Dimorphandra mollis (Fabaceae, Caesalpinioideae)," Biological Research, vol. 43, no. 1, pp. 63-74, 2010.

[54] Q. Q. Lv, W. J. Wu, X. L. Guo et al., “Antidepressant activity of astilbin: involvement of monoaminergic neurotransmitters and BDNF signal pathway," Biological and Pharmaceutical Bulletin, vol. 37, no. 6, pp. 987-995, 2014.

[55] X. Wu, J. Wu, S. Xia, B. Li, and J. Dong, "Icaritin opposes the development of social aversion after defeat stress via increases of GR mRNA and BDNF mRNA in mice," Behavioural Brain Research, vol. 256, pp. 602-608, 2013.

[56] B. Liu, C. Xu, X. Wu et al., "Icariin exerts an antidepressant effect in an unpredictable chronic mild stress model of depression in rats and is associated with the regulation of hippocampal neuroinflammation," Neuroscience, vol. 294, pp. 193-205, 2015.

[57] K. Wei, Y. Xu, Z. Zhao et al., "Icariin alters the expression of glucocorticoid receptor, FKBP5 and SGK1 in rat brains following exposure to chronic mild stress," International Journal of Molecular Medicine, vol. 38, no. 1, pp. 337344,2016

[58] X. Liu, Q. Qi, G. Xiao, J. Li, H. R. Luo, and K. Ye, “O-methylated metabolite of 7,8-dihydroxyflavone activates TrkB receptor and displays antidepressant activity," Pharmacology, vol. 91, no. 3-4, pp. 185-200, 2013.

[59] S.-W. Jang, X. Liu, M. Yepes et al., "A selective TrkB agonist with potent neurotrophic activities by 7,8-dihydroxyflavone," Proceedings of the National Academy of Sciences, vol. 107, no. 6, pp. 2687-2692, 2010.

[60] X. Liu, C. B. Chan, S. W. Jang et al., "A synthetic 7,8-dihydroxyflavone derivative promotes neurogenesis and exhibits potent antidepressant effect," Journal of Medicinal Chemistry, vol. 53, no. 23, pp. 8274-8286, 2010.

[61] M. Zheng, C. Liu, F. Pan, D. Shi, and Y. Zhang, "Antidepressant-like effect of hyperoside isolated from Apocynum 
venetum leaves: possible cellular mechanisms," Phytomedicine, vol. 19, no. 2, pp. 145-149, 2012.

[62] J. S. Haas, E. D. Stolz, A. H. Betti et al., "The anti-immobility effect of hyperoside on the forced swimming test in rats is mediated by the D2-like receptors activation," Planta Medica, vol. 77, no. 4, pp. 334-339, 2011.

[63] C. Liu, J. Wu, J. Gu et al., "Baicalein improves cognitive deficits induced by chronic cerebral hypoperfusion in rats," Pharmacology Biochemistry and Behavior, vol. 86, no. 3, pp. 423430, 2007.

[64] D. E. Shieh, L. T. Liu, and C. C. Lin, "Antioxidant and free radical scavenging effects of baicalein, baicalin and wogonin," Anticancer Research, vol. 20, no. 5A, pp. 2861-2865, 2000.

[65] Z. Xiong, B. Jiang, P. F. Wu et al., "Antidepressant effects of a plant-derived flavonoid baicalein involving extracellular signal-regulated kinases cascade," Biological and Pharmaceutical Bulletin, vol. 34, no. 2, pp. 253-259, 2011.

[66] L. F. Li, J. Yang, S. P. Ma, and R. Qu, "Magnolol treatment reversed the glial pathology in an unpredictable chronic mild stress-induced rat model of depression," European Journal of Pharmacology, vol. 711, no. 1-3, pp. 42-49, 2013.

[67] M. Nakajima, M. Ogawa, Y. Amakura, M. Yoshimura, S. Okuyama, and Y. Furukawa, "3,5,6,7,8,3',4'-Heptamethoxyflavone reduces interleukin-4 production in the spleen cells of mice," Biomedical Research, vol. 37, no. 2, pp. 95-99, 2016.

[68] S. Okuyama, M. Morita, K. Miyoshi et al., “3,5,6,7,8,3’,4'-Heptamethoxyflavone, a citrus flavonoid, on protection against memory impairment and neuronal cell death in a global cerebral ischemia mouse model," Neurochemistry International, vol. 70, pp. 30-38, 2014.

[69] A. Sawamoto, S. Okuyama, K. Yamamoto et al., “3,5,6,7,8,3',4 '-Heptamethoxyflavone, a citrus flavonoid, ameliorates corticosterone-induced depression-like behavior and restores brain-derived neurotrophic factor expression, neurogenesis, and neuroplasticity in the hippocampus," Molecules, vol. 21, pp. 1-13, 2016.

[70] C. Grosso, P. Valentão, and P. B. Andrade, "Depressive disorders: prevalence, costs, and theories," in Herbal Medicine in Depression: Traditional Medicine to Innovative Drug Delivery, C. Grosso, Ed., pp. 1-41, Springer International Publishing, Cham, 2016.

[71] S. Jeon and Y. K. Kim, "Molecular neurobiology and promising new treatment in depression," International Journal of Molecular Sciences, vol. 17, no. 3, p. 381, 2016.

[72] M. Freitas, D. Ribeiro, S. M. Tomé, A. M. S. Silva, and E. Fernandes, "Synthesis of chlorinated flavonoids with anti-inflammatory and pro-apoptotic activities in human neutrophils," European Journal of Medicinal Chemistry, vol. 86, pp. 153-164, 2014.

[73] L. H. Mai, G. G. Chabot, P. Grellier et al., "Antivascular and anti-parasite activities of natural and hemisynthetic flavonoids from New Caledonian Gardenia species (Rubiaceae)," European Journal of Medicinal Chemistry, vol. 93, pp. 93100, 2015.

[74] J. Cassani, A. Dorantes-Barrón, L. Novales, G. Real, and R. Estrada-Reyes, "Anti-depressant-like effect of kaempferitrin isolated from Justicia spicigera Schltdl (Acanthaceae) in two behavior models in mice: evidence for the involvement of the serotonergic system," Molecules, vol. 19, no. 12, pp. 21442-21461, 2014.
[75] B. Du, X. Tang, F. Liu et al., "Antidepressant-like effects of the hydroalcoholic extracts of Hemerocallis citrina and its potential active components," BMC Complementary and Alternative Medicine, vol. 14, no. 1, 2014.

[76] D. G. Machado, L. E. B. Bettio, M. P. Cunha et al., "Antidepressant-like effect of rutin isolated from the ethanolic extract from Schinus molle L. in mice: evidence for the involvement of the serotonergic and noradrenergic systems," European Journal of Pharmacology, vol. 587, no. 1-3, pp. 163-168, 2008.

[77] L. C. Souza, M. G. de Gomes, A. T. R. Goes et al., "Evidence for the involvement of the serotonergic $5-\mathrm{HT}_{1 \mathrm{~A}}$ receptors in the antidepressant-like effect caused by hesperidin in mice," Progress in Neuro-Psychopharmacology and Biological Psychiatry, vol. 40, pp. 103-109, 2013.

[78] C. B. Filho, L. Del Fabbro, M. G. de Gomes et al., "Kappa-opioid receptors mediate the antidepressant-like activity of hesperidin in the mouse forced swimming test," European Journal of Pharmacology, vol. 698, no. 1-3, pp. 286-291, 2013.

[79] M. Ishisaka, K. Kakefuda, M. Yamauchi et al., "Luteolin shows an antidepressant-like effect via suppressing endoplasmic reticulum stress," Biological and Pharmaceutical Bulletin, vol. 34, no. 9, pp. 1481-1486, 2011.

[80] J. B. I. De la Peña, C. A. Kim, H. L. Lee et al., "Luteolin mediates the antidepressant-like effects of Cirsium japonicum in mice, possibly through modulation of the GABA receptor," Archives of Pharmacal Research, vol. 37, no. 2, pp. 263-269, 2014.

[81] O. D. Can, U. Demir Ozkay, and U. I. Uçel, “Anti-depressantlike effect of vitexin in BALB/c mice and evidence for the involvement of monoaminergic mechanisms," European Journal of Pharmacology, vol. 699, no. 1-3, pp. 250-257, 2013.

[82] J. P. Kim, I. S. Lee, J. J. Seo et al., "Vitexin, orientin and other flavonoids from Spirodela polyrhiza inhibit adipogenesis in 3T3-L1 cells," Phytotherapy Research, vol. 24, no. 10, pp. 1543-1548, 2010.

[83] F. U. Afifi and R. Abu-Dahab, "Phytochemical screening and biological activities of Eminium spiculatum (Blume) Kuntze (family Araceae)," Natural Product Research, vol. 26, no. 9, pp. 878-882, 2012.

[84] H. Li, F. Song, J. Xing, R. Tsao, Z. Liu, and S. Liu, "Screening and structural characterization of $\alpha$-glucosidase inhibitors from hawthorn leaf flavonoids extract by ultrafiltration LCDAD-MS ${ }^{n}$ and SORI-CID FTICR MS," Journal of the American Society for Mass Spectrometry, vol. 20, no. 8, pp. 14961503, 2009.

[85] S. Perveen, A. M. El-Shafae, A. Al-Taweel et al., "Antioxidant and urease inhibitory $C$-glycosylflavonoids from Celtis africana," Journal of Asian Natural Products Research, vol. 13, no. 9, pp. 799-804, 2011.

[86] Y. Zhou, Y. E. Liu, J. Cao et al., "Vitexins, nature-derived lignan compounds, induce apoptosis and suppress tumor growth," Clinical Cancer Research, vol. 15, no. 16, pp. 51615169, 2009.

[87] X. Peng, Z. Zheng, K. W. Cheng et al., "Inhibitory effect of mung bean extract and its constituents vitexin and isovitexin on the formation of advanced glycation endproducts," Food Chemistry, vol. 106, no. 2, pp. 475-481, 2008.

[88] M. Prabhakar, H. Bano, I. Kumar, M. Shamsi, and S. Khan, "Pharmacological investigations on vitexin," Planta Medica, vol. 43, no. 12, pp. 396-403, 1981. 
[89] S. Gorzalczany, C. Marrassini, J. Miño, C. Acevedo, and G. Ferraro, "Antinociceptive activity of ethanolic extract and isolated compounds of Urtica circularis," Journal of Ethnopharmacology, vol. 134, no. 3, pp. 733-738, 2011.

[90] D. H. Shin, Y. C. Bae, J. S. Kim-Han et al., "Polyphenol amentoflavone affords neuroprotection against neonatal hypoxicischemic brain damage via multiple mechanisms," Journal of Neurochemistry, vol. 96, no. 2, pp. 561-572, 2006.

[91] I. O. Ishola, M. Chatterjee, S. Tota et al., “Antidepressant and anxiolytic effects of amentoflavone isolated from Cnestis ferruginea in mice," Pharmacology Biochemistry and Behavior, vol. 103, no. 2, pp. 322-331, 2012.

[92] V. Zbarsky, K. P. Datla, S. Parkar, D. K. Rai, O. I. Aruoma, and D. T. Dexter, "Neuroprotective properties of the natural phenolic antioxidants curcumin and naringenin but not quercetin and fisetin in a 6-OHDA model of Parkinson's disease," Free Radical Research, vol. 39, no. 10, pp. 1119-1125, 2005.

[93] L. T. Yi, C. F. Li, X. Zhan et al., "Involvement of monoaminergic system in the antidepressant-like effect of the flavonoid naringenin in mice," Progress in Neuro-Psychopharmacology and Biological Psychiatry, vol. 34, no. 7, pp. 1223-1228, 2010.

[94] L. T. Yi, J. Li, H. C. Li et al., “Antidepressant-like behavioral, neurochemical and neuroendocrine effects of naringenin in the mouse repeated tail suspension test," Progress in NeuroPsychopharmacology and Biological Psychiatry, vol. 39, no. 1, pp. 175-181, 2012.

[95] K. Ishige, D. Schubert, and Y. Sagara, "Flavonoids protect neuronal cells from oxidative stress by three distinct mechanisms," Free Radical Biology \& Medicine, vol. 30, no. 4, pp. 433-446, 2001.

[96] D. E. Brash and P. A. Havre, "New careers for antioxidants," Proceedings of the National Academy of Sciences, vol. 99, no. 22, pp. 13969-13971, 2002.

[97] L. Zhen, J. Zhu, X. Zhao et al., "The antidepressant-like effect of fisetin involves the serotonergic and noradrenergic system," Behavioural Brain Research, vol. 228, no. 2, pp. 359366, 2012.

[98] X. Yu, X. Jiang, X. Zhang et al., "The effects of fisetin on lipopolysaccharide-induced depressive-like behavior in mice," Metabolic Brain Disease, vol. 31, no. 5, pp. 10111021, 2016.

[99] K. Matsuzaki, T. Yamakuni, M. Hashimoto et al., "Nobiletin restoring $\beta$-amyloid-impaired CREB phosphorylation rescues memory deterioration in Alzheimer's disease model rats," Neuroscience Letters, vol. 400, no. 3, pp. 230-234, 2006.

[100] H. Onozuka, A. Nakajima, K. Matsuzaki et al., "Nobiletin, a citrus flavonoid, improves memory impairment and $\mathrm{A} \beta$ pathology in a transgenic mouse model of Alzheimer's disease," Journal of Pharmacology and Experimental Therapeutics, vol. 326, no. 3, pp. 739-744, 2008.

[101] Y. Yamamoto, N. Shioda, F. Han et al., "Nobiletin improves brain ischemia-induced learning and memory deficits through stimulation of CaMKII and CREB phosphorylation," Brain Research, vol. 1295, pp. 218-229, 2009.

[102] L. T. Yi, H. L. Xu, J. Feng, X. Zhan, L. P. Zhou, and C. C. Cui, "Involvement of monoaminergic systems in the antidepressant-like effect of nobiletin," Physiology \& Behavior, vol. 102, no. 1, pp. 1-6, 2011.

[103] A. Kahraman, H. Çakar, and T. Köken, “The protective effect of quercetin on long-term alcohol consumption-induced oxidative stress," Molecular Biology Reports, vol. 39, no. 3, pp. 2789-2794, 2012.

[104] A. W. Boots, G. R. M. M. Haenen, and A. Bast, "Health effects of quercetin: from antioxidant to nutraceutical," European Journal of Pharmacology, vol. 585, no. 2-3, pp. 325-337, 2008.

[105] E. A. Demir, H. S. Gergerlioglu, and M. Oz, "Antidepressantlike effects of quercetin in diabetic rats are independent of hypothalamic-pituitary-adrenal axis," Acta Neuropsychiatrica, vol. 28, no. 1, pp. 23-30, 2016.

[106] S. Scheggi, A. Marandino, D. Del Monte et al., "The protective effect of Hypericum connatum on stress-induced escape deficit in rat is related to its flavonoid content," Pharmaceutical Biology, vol. 54, no. 9, pp. 1782-1792, 2016.

[107] P. Rinwa and A. Kumar, "Quercetin suppress microglial neuroinflammatory response and induce antidepressent-like effect in olfactory bulbectomized rats," Neuroscience, vol. 255, pp. 86-98, 2013.

[108] B. Singh, D. Singh, and R. K. Goel, "Dual protective effect of Passiflora incarnata in epilepsy and associated post-ictal depression," Journal of Ethnopharmacology, vol. 139, no. 1, pp. 273-279, 2012.

[109] F. Donato, C. B. Filho, R. Giacomeli et al., "Evidence for the involvement of potassium channel inhibition in the antidepressant-like effects of hesperidin in the tail suspension test in mice," Journal of Medicinal Food, vol. 18, no. 7, pp. 818-823, 2015.

[110] M. S. Antunes, C. R. Jesse, J. R. Ruff et al., "Hesperidin reverses cognitive and depressive disturbances induced by olfactory bulbectomy in mice by modulating hippocampal neurotrophins and cytokine levels and acetylcholinesterase activity," European Journal of Pharmacology, vol. 789, pp. 411-420, 2016.

[111] Y. Z. Zhou, X. Li, W. X. Gong et al., "Protective effect of isoliquiritin against corticosterone-induced neurotoxicity in PC12 cells," Food \& Function, vol. 8, no. 3, pp. 1235-1244, 2017.

[112] C. F. Ortmann, H. M. Abelaira, G. Z. Réus et al., "LC/QTOF profile and preliminary stability studies of an enriched flavonoid fraction of Cecropia pachystachya Trécul leaves with potential antidepressant-like activity," Biomedical Chromatography, vol. 31, no. 11, 2017.

[113] Y. Bandaruk, R. Mukai, T. Kawamura, H. Nemoto, and J. Terao, "Evaluation of the inhibitory effects of quercetinrelated flavonoids and tea catechins on the monoamine oxidase-A reaction in mouse brain mitochondria," Journal of Agricultural and Food Chemistry, vol. 60, no. 41, pp. 10270-10277, 2012.

[114] W. Huang, Z. Chen, Q. Wang et al., "Piperine potentiates the antidepressant-like effect of trans-resveratrol: involvement of monoaminergic system," Metabolic Brain Disease, vol. 28, no. 4, pp. 585-595, 2013.

[115] A. I. Oliveira, C. Pinho, B. Sarmento, and A. C. P. Dias, "Neuroprotective activity of Hypericum perforatum and its major components," Frontiers in Plant Science, vol. 7, 2016.

[116] S. D. S. Banjarnahor and N. Artanti, "Antioxidant properties of flavonoids," Medical Journal of Indonesia, vol. 23, no. 4, p. 239, 2015.

[117] S. R. K. M. Hewage, M. J. Piao, K. A. Kang et al., "Hesperidin attenuates ultraviolet $\mathrm{B}$-induced apoptosis by mitigating oxidative stress in human keratinocytes," Biomolecules \& Therapeutics, vol. 24, no. 3, pp. 312-319, 2016. 
[118] C. Zhu, Y. Dong, H. Liu, H. Ren, and Z. Cui, "Hesperetin protects against $\mathrm{H}_{2} \mathrm{O}_{2}$-triggered oxidative damage via upregulation of the Keap1-Nrf2/HO-1 signal pathway in ARPE-19 cells," Biomedicine \& Pharmacotherapy, vol. 88, pp. 124-133, 2017.

[119] P. S. Arwa, M. L. Zeraik, V. F. Ximenes, L. M. da Fonseca, V. da Silva Bolzani, and D. H. S. Silva, "Redox-active biflavonoids from Garcinia brasiliensis as inhibitors of neutrophil oxidative burst and human erythrocyte membrane damage," Journal of Ethnopharmacology, vol. 174, pp. 410-418, 2015.

[120] E. J. Jeong, L. Hwang, M. Lee, K. Y. Lee, M. J. Ahn, and S. H. Sung, "Neuroprotective biflavonoids of Chamaecyparis obtusa leaves against glutamate-induced oxidative stress in HT22 hippocampal cells," Food and Chemical Toxicology, vol. 64, pp. 397-402, 2014.

[121] L. Chen, B. Zhang, S. Shan, and X. Zhao, "Neuroprotective effects of vitexin against isoflurane-induced neurotoxicity by targeting the TRPV1 and NR2B signaling pathways," Molecular Medicine Reports, vol. 14, no. 6, pp. 5607-5613, 2016.

[122] C. S. Huang, C. K. Lii, A. H. Lin et al., "Protection by chrysin, apigenin, and luteolin against oxidative stress is mediated by the Nrf2-dependent up-regulation of heme oxygenase 1 and glutamate cysteine ligase in rat primary hepatocytes," Archives of Toxicology, vol. 87, no. 1, pp. 167-178, 2013.

[123] Y. Chtourou, A. B. Slima, R. Gdoura, and H. Fetoui, "Naringenin mitigates iron-induced anxiety-like behavioral impairment, mitochondrial dysfunctions, ectonucleotidases and acetylcholinesterase alteration activities in rat hippocampus," Neurochemical Research, vol. 40, no. 8, pp. 1563-1575, 2015.

[124] H. P. Ma, X. N. Ma, B. F. Ge et al., "Icariin attenuates hypoxia-induced oxidative stress and apoptosis in osteoblasts and preserves their osteogenic differentiation potential in vitro," Cell Proliferation, vol. 47, no. 6, pp. 527-539, 2014.

[125] B. Wang, Q. Zhang, R. Yao, X. Liu, and Z. Qu, "7, 8Dihydroxyflavone protects an endothelial cell line from $\mathrm{H}_{2} \mathrm{O}_{2}$ damage," PLoS One, vol. 10, no. 8, article e0135345, 2015.

[126] X. L. Hao, Y. Kang, J. K. Li, Q. S. Li, E. L. Liu, and X. X. Liu, "Protective effects of hyperoside against $\mathrm{H} 2 \mathrm{O} 2$-induced apoptosis in human umbilical vein endothelial cells," Molecular Medicine Reports, vol. 14, no. 1, pp. 399-405, 2016.

[127] E. O. Choi, J. W. Jeong, C. Park et al., "Baicalein protects C6 glial cells against hydrogen peroxide-induced oxidative stress and apoptosis through regulation of the Nrf2 signaling pathway," International Journal of Molecular Medicine, vol. 37, no. 3, pp. 798-806, 2016.

[128] M. M. J. P. E. Sthijns, P. M. Schiffers, G. M. Janssen et al., "Rutin protects against $\mathrm{H}_{2} \mathrm{O}_{2}$-triggered impaired relaxation of placental arterioles and induces Nrf2-mediated adaptation in human umbilical vein endothelial cells exposed to oxidative stress," Biochimica et Biophysica Acta (BBA) - General Subjects, vol. 1861, no. 5, pp. 1177-1189, 2017.

[129] H. Chang, C. Li, K. Huo et al., "Luteolin prevents $\mathrm{H}_{2} \mathrm{O}_{2}$ induced apoptosis in $\mathrm{H} 9 \mathrm{C} 2$ cells through modulating AktP53/Mdm2 signaling pathway," BioMed Research International, vol. 2016, Article ID 5125836, 9 pages, 2016.

[130] J. H. Yen, P. S. Wu, S. F. Chen, and M. J. Wu, "Fisetin protects PC12 cells from tunicamycin-mediated cell death via reactive oxygen species scavenging and modulation of Nrf2-driven gene expression, SIRT1 and MAPK signaling in PC12 cells," International Journal of Molecular Sciences, vol. 18, no. 4, p. 852, 2017.
[131] A. Murakami and H. Ohigashi, "Cancer-preventive antioxidants that attenuate free radical generation by inflammatory cells," Biological Chemistry, vol. 387, no. 4, pp. 387392, 2006.

[132] J. C. R. Vellosa, L. O. Regasini, C. Belló et al., "Preliminary in vitro and ex vivo evaluation of afzelin, kaempferitrin and pterogynoside action over free radicals and reactive oxygen species," Archives of Pharmacal Research, vol. 38, no. 6, pp. 1168-1177, 2015.

[133] D. Bao, J. Wang, X. Pang, and H. Liu, "Protective effect of quercetin against oxidative stress-induced cytotoxicity in rat pheochromocytoma (PC-12) cells," Molecules, vol. 22, no. 7, p. 1122, 2017.

[134] J. Liu, X. Li, J. Lin et al., “Sarcandra glabra (Caoshanhu) protects mesenchymal stem cells from oxidative stress: a bioevaluation and mechanistic chemistry," BMC Complementary and Alternative Medicine, vol. 16, no. 1, p. 423, 2016.

[135] A. Primikyri, G. Mazzone, C. Lekka, A. G. Tzakos, N. Russo, and I. P. Gerothanassis, "Understanding zinc(II) chelation with quercetin and luteolin: a combined NMR and theoretical study," The Journal of Physical Chemistry B, vol. 119, no. 1, pp. 83-95, 2015.

[136] M. N. I. Bhuiyan, S. Mitsuhashi, K. Sigetomi, and M. Ubukata, "Quercetin inhibits advanced glycation end product formation via chelating metal ions, trapping methylglyoxal, and trapping reactive oxygen species," Bioscience, Biotechnology, and Biochemistry, vol. 81, no. 5, pp. 882-890, 2017.

[137] F. Alam, Q. N. Saqib, and M. Ashraf, “Gaultheria trichophylla (Royle): a source of minerals and biologically active molecules, its antioxidant and anti-lipoxygenase activities," $B M C$ Complementary and Alternative Medicine, vol. 17, no. 1, p. 3, 2017.

[138] H. Cao, J. M. Pauff, and R. Hille, "X-ray crystal structure of a xanthine oxidase complex with the flavonoid inhibitor quercetin," Journal of Natural Products, vol. 77, no. 7, pp. 16931699, 2014.

[139] H. Cao, B. Chen, Y. Deng, X. Lu, and G. Yu, "Baicalin increases the antioxidant capacity via promoting the nuclear translocation of NF-E2-related factor 2 (Nrf2) in N2a/ APPswe cells," Chinese Journal of Cellular and Molecular Immunology, vol. 31, no. 12, pp. 1597-1601, 2015.

[140] K. Kaltalioglu and S. Coskun-Cevher, "Potential of morin and hesperidin in the prevention of cisplatin-induced nephrotoxicity," Renal Failure, vol. 38, no. 8, pp. 1291-1299, 2016.

[141] L. N. Bodduluru, E. R. Kasala, R. M. Madhana et al., "Naringenin ameliorates inflammation and cell proliferation in benzo(a)pyrene induced pulmonary carcinogenesis by modulating CYP1A1, NF $\kappa \mathrm{B}$ and PCNA expression," International Immunopharmacology, vol. 30, pp. 102-110, 2016.

[142] S. Kim, Y. W. Chin, and J. Cho, "Protection of cultured cortical neurons by luteolin against oxidative damage through inhibition of apoptosis and induction of heme oxygenase1," Biological and Pharmaceutical Bulletin, vol. 40, no. 3, pp. 256-265, 2017.

[143] R. Kabirifar, Z. Ghoreshi, F. Safari, A. Karimollah, A. Moradi, and E. Eskandari-Nasab, "Quercetin protects liver injury induced by bile duct ligation via attenuation of Racl and NADPH oxidase 1 expression in rats," Hepatobiliary \& Pancreatic Diseases International, vol. 16, no. 1, pp. 88-95, 2017.

[144] H. Ihara, H. Yamamoto, T. Ida et al., "Inhibition of nitric oxide production and inducible nitric oxide synthase 
expression by a polymethoxyflavone from young fruits of Citrus unshiu in rat primary astrocytes," Bioscience, Biotechnology, and Biochemistry, vol. 76, no. 10, pp. 1843-1848, 2012.

[145] W. N. Marsden, "Synaptic plasticity in depression: molecular, cellular and functional correlates," Progress in NeuroPsychopharmacology and Biological Psychiatry, vol. 43, pp. 168-184, 2013.

[146] M. Banasr, J. M. Dwyer, and R. S. Duman, "Cell atrophy and loss in depression: reversal by antidepressant treatment," Current Opinion in Cell Biology, vol. 23, no. 6, pp. 730-737, 2011.

[147] A. Sawamoto, S. Okuyama, Y. Amakura et al., “3,5,6,7,8,3' , $4^{\prime}$-Heptamethoxyflavone ameliorates depressive-like behavior and hippocampal neurochemical changes in chronic unpredictable mild stressed mice by regulating the brain-derived neurotrophic factor: requirement for ERK activation," International Journal of Molecular Sciences, vol. 18, no. 10, p. 2133, 2017.

[148] M. Shirai, Y. Kawai, R. Yamanishi, and J. Terao, "Approach to novel functional foods for stress control 5. Antioxidant activity profiles of antidepressant herbs and their active components," The Journal of Medical Investigation, vol. 52, Supplement, pp. 249-251, 2005.

[149] S. Carradori, M. C. Gidaro, A. Petzer et al., "Inhibition of human monoamine oxidase: biological and molecular modeling studies on selected natural flavonoids," Journal of Agricultural and Food Chemistry, vol. 64, no. 47, pp. 9004-9011, 2016.

[150] R. Pingili, S. Vemulapalli, S. S. Mullapudi, S. Nuthakki, S. Pendyala, and N. Kilaru, "Pharmacokinetic interaction study between flavanones (hesperetin, naringenin) and rasagiline mesylate in wistar rats," Drug Development and Industrial Pharmacy, vol. 42, no. 7, pp. 1110-1117, 2016.

[151] L. H. Martini, F. Jung, F. A. Soares et al., "Naturally occurring compounds affect glutamatergic neurotransmission in rat brain," Neurochemical Research, vol. 32, no. 11, pp. 19501956, 2007. 


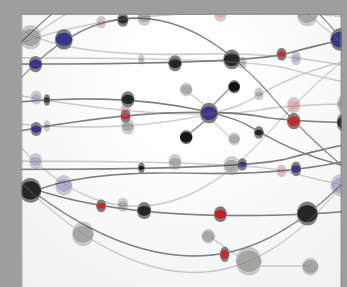

The Scientific World Journal
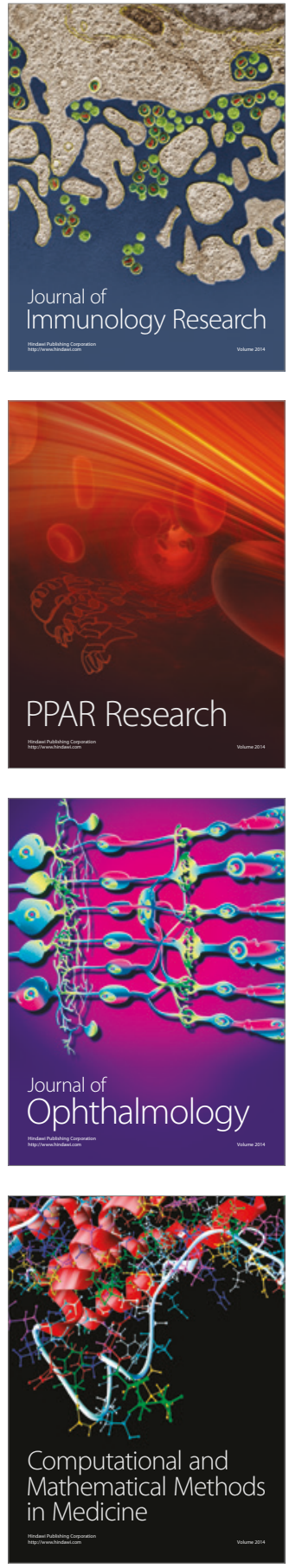

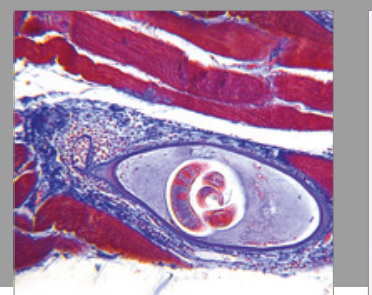

Gastroenterology Research and Practice
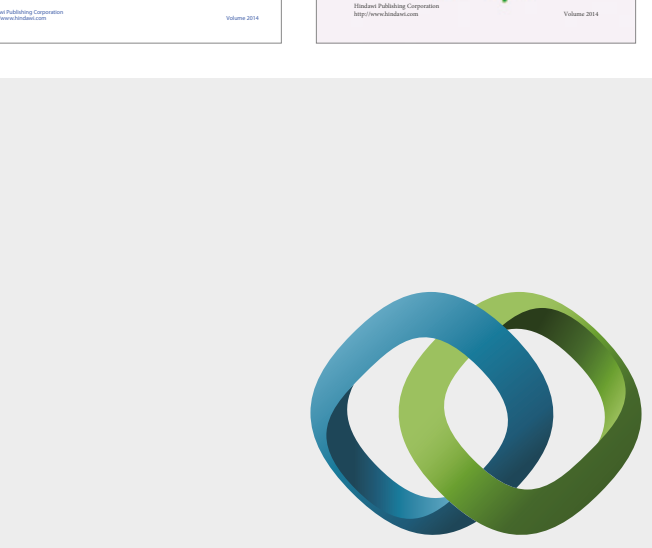

\section{Hindawi}

Submit your manuscripts at

https://www.hindawi.com
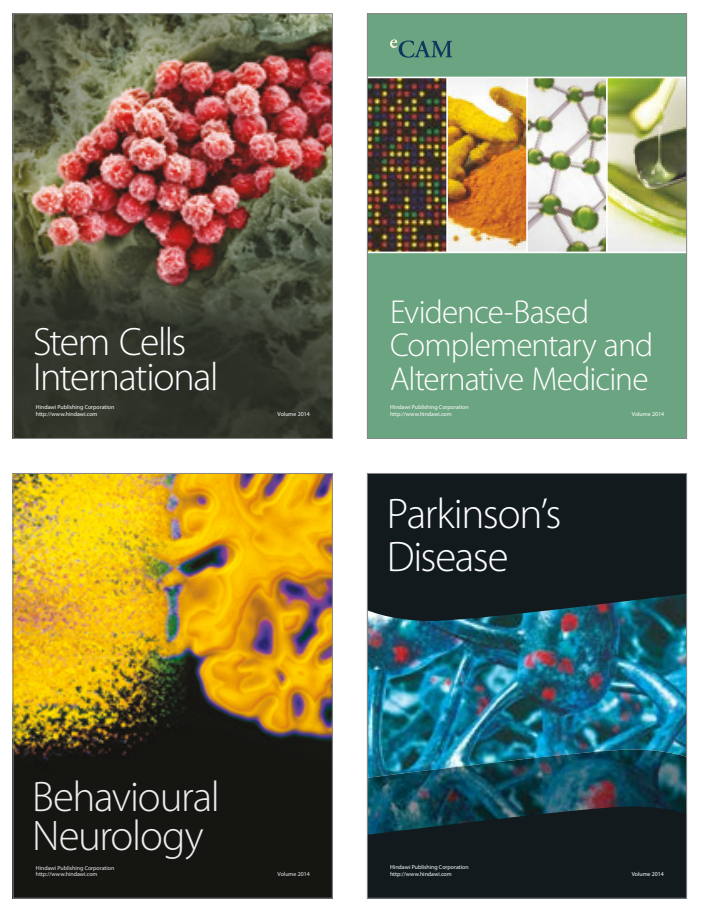
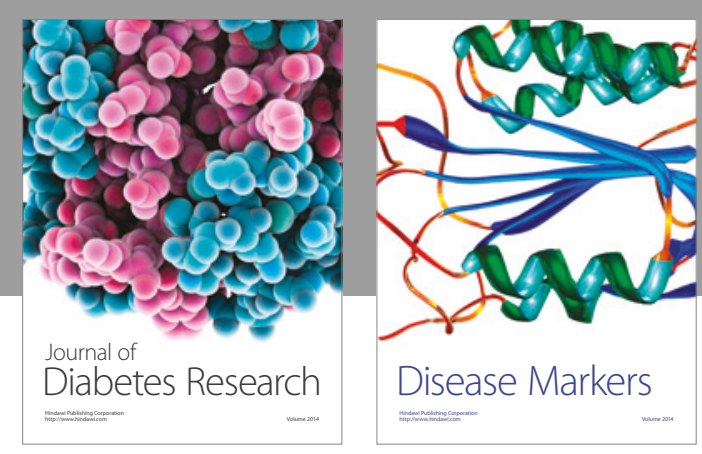

Disease Markers
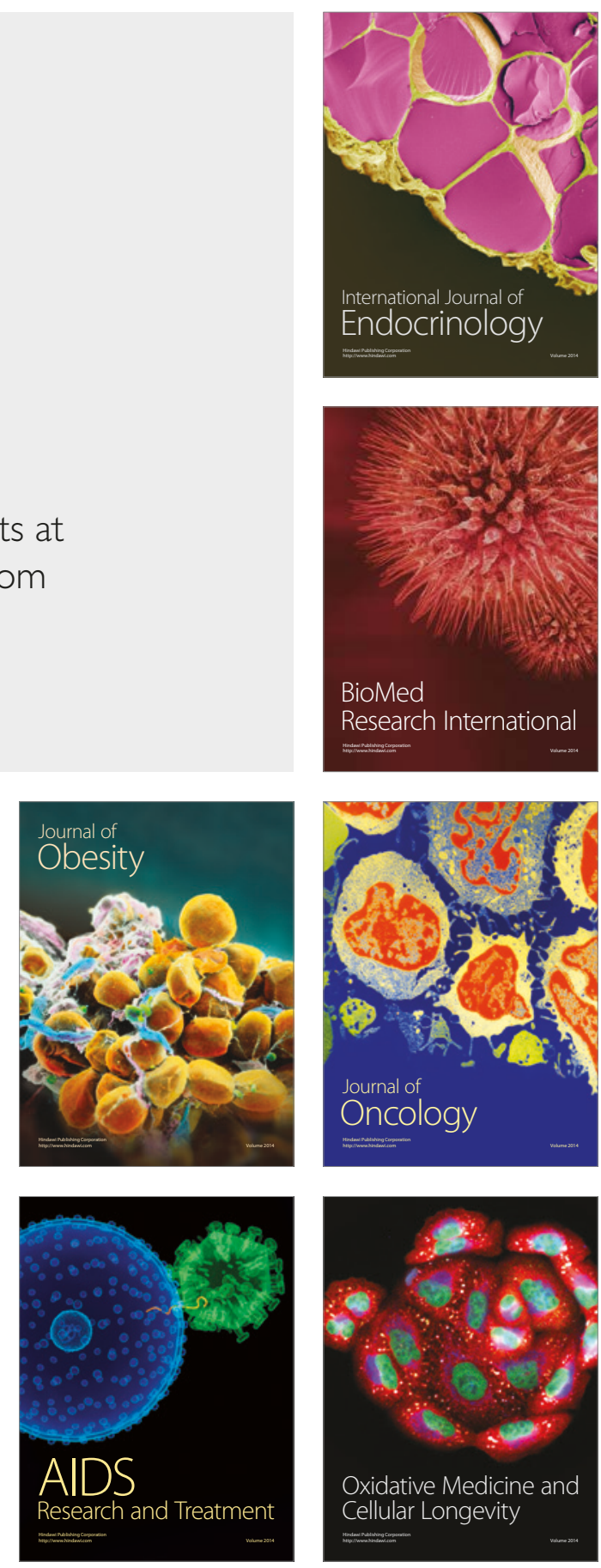